\title{
1 Monophyly of Diverse Bigyromonadea and their Impact on Phylogenomic Relationships
}

\section{Within Stramenopiles}

4 Anna Cho ${ }^{\mathrm{a}}$, Denis V. Tikhonenkov ${ }^{\mathrm{a}, \mathrm{b}}$, Elisabeth Hehenberger ${ }^{\mathrm{c}, \mathrm{d}}$ Anna Karnkowska ${ }^{\mathrm{e}}$, Alexander P.

5 Mylnikov $^{\mathrm{b}}$, Patrick J. Keeling ${ }^{\mathrm{a}}$

6

$7{ }^{\mathrm{a}}$ Department of Botany, University of British Columbia, Vancouver V6T 1Z4, British Columbia, 8 Canada

$9 \quad{ }^{b}$ Papanin Institute for Biology of Inland Waters, Russian Academy of Science, Borok 152742,

10 Russia

$11{ }^{\mathrm{c}}$ Ocean EcoSystems Biology Group, GEOMAR, Helmholtz Centre for Ocean Research, Kiel 12 24105, Germany

13 Institute of Parasitology, Biology Centre, Czech Academy of Sciences, 37005 České

14 Budějovice, Czech Republic

15 e Institute of Evolutionary Biology, Faculty of Biology, Biological and Chemical Research

16 Centre, University of Warsaw, Warsaw 02-089, Poland

17

18

19 Keywords: Bigyromonadea; Developea; Pirsoniales; Oomycetes; Phagoheterotrophs;

20 Stramenopile; Phylogenomics; Aggregation; Zoospores; Single-cell transcriptome 


\section{Abstract}

Stramenopiles are a diverse but relatively well-studied eukaryotic supergroup with

23 considerable genomic information available (Sibbald and Archibald, 2017). Nevertheless, the

24 relationships between major stramenopile subgroups remain unresolved, in part due to a lack of

25 data from small nanoflagellates that make up a lot of the genetic diversity of the group. This is

26 most obvious in Bigyromonadea, which is one of four major stramenopile subgroups but

27 represented by a single transcriptome. To examine the diversity of Bigyromonadea and how the

28 lack of data affects the tree, we generated transcriptomes from seven novel bigyromonada

29 species described in this study: Develocauda condao, Develocanicus komovi, Develocanicus

30 vyazemskyi, Cubaremonas variflagellatum, Pirsonia chemainus, Feodosia pseudopoda, and

31 Koktebelia satura. Both maximum likelihood and Bayesian phylogenomic trees based on a 247

32 gene-matrix recovered a monophyletic Bigyromonadea that includes two diverse subgroups,

33 Developea and Pirsoniales, that were not previously related based on single gene trees.

34 Maximum likelihood analyses show Bigyromonadea related to oomycetes, whereas Bayesian

35 analyses and topology testing were inconclusive. We observed similarities between the novel

36 bigyromonad species and motile zoospores of oomycetes in morphology and the ability to self-

37 aggregate. Rare formation of pseudopods and fused cells were also observed, traits that are also

38 found in members of labyrinthulomycetes, another osmotrophic stramenopiles. Furthermore, we

39 report the first case of eukaryovory in the flagellated stages of Pirsoniales. These analyses reveal

40 new diversity of Bigyromonadea, and altogether suggest their monophyly with oomycetes,

41 collectively known as Pseudofungi, is the most likely topology of the stramenopile tree. 


\section{Introduction}

Stramenopiles (= Heterokonts) are one of the well-characterized members of the eukaryotic supergroup SAR (Stramenopila, Alveolate, Rhizaria) (Keeling and Burki, 2019). Stramenopiles are very diverse, comprising photoautotrophs (i.e. heterokont algae in ochrophytes), osmotrophic oomycetes and labyrinthulomycetes with a motile zoospore life-stage (e.g. Phytophthora sp., Pythium sp., and labyrinthulids), and, free-living phagotrophic opalozoans (e.g. Cafeteria roenbergensis, Cantina marsupialis) that occupy a broad range of

51 environments (Cavalier-Smith and Chao, 2006; Cavalier-Smith and Scoble, 2013a; Kolodziej and Stoeck, 2007; Stiller et al., 2009; Tsui et al., 2009). Stramenopiles can be largely classified

53 into two major groups: Gyrista consisting of Ochrophyta, Oomycota, and Bigyromonadea; and

54 Bigyra consisting of Sagenista and Opalozoa. A single species Platysulcus tardus, has also

55 recently been shown to be a basal stramenopile (Thakur et al., 2019). While there is a lot of

56 genomic data from stramenopiles, only a handful comes from phagoheterotrophs (Mitra et al.,

57 2016), despite them representing much of the diversity as well as being key outstanding

58 problems in resolving controversies in stramenopiles phylogeny (Burki et al., 2016; Derelle et

59 al., 2016; Leonard et al., 2018; Shiratori et al., 2017, 2015).

One such clade is the subphylum Bigyromonadea, which was proposed to include the

61 class Developea (Aleoshin et al., 2016) and order Pirsoniales (Cavalier-Smith, 1998). The

62 monophyly of the Bigyromonadea is essentially untested, since only small subunit rRNA (SSU)

63 data are known from all but a single species (the exception being Developayella elegans, for

64 which a transcriptome is available), and the two groups never branch together in SSU

65 phylogenies (Aleoshin et al., 2016; Cavalier-Smith and Chao, 2006; Kühn et al., 2004; Weiler et

66 al., 2020). 
Developea are marine bacterivores, including Developayella elegans (Leipe et al., 1996;

68 Tong, 1995) and Mediocremonas mediterraneus (Weiler et al., 2020), and the marine

69 eukaryovore Develorapax marinus (Aleoshin et al., 2016). Pirsoniales are parasites of other

70 microbes, including Pirsonia guinardiae (Schnepf et al., 1990) and P. punctigera (Schweikert

71 and Schnepf, 1997). These parasites deploy a pseudopod to squeeze through the frustule girdles

72 of their diatom host, while the main cell body (auxosome) stays outside of the host. The invading

73 pseudopod then phagocytoses the host cytoplasm or chloroplasts forming a trophosome (food

74 vacuole), which is then transported out to the auxosome (Kühn et al., 2004; Schnepf et al., 1990).

75 The relationship of both groups to other stramenopiles is uncertain, and both have led to

76 hypotheses about the evolution of other related groups. For example, the eukaryovory of $D$.

77 marinus and its placement in rRNA trees has led to the hypothesis that it represents a model for a

78 phagoheterotrophic ochrophyte ancestor (Aleoshin et al., 2016), however its position in the tree

79 varies between grouping with ochrophytes (Leonard et al., 2018) or oomycetes (Noguchi et al.,

80 2016; Thakur et al., 2019). Pirsoniales have also been found branching as sister to ochrophytes

81 based on SSU rRNA trees (Aleoshin et al., 2016; Kühn et al., 2004), although once again not

82 consistently and without strong support.

83 To test for the monopoly of bigyromonads and more thoroughly examine their

84 relationship to other stramenopiles, we significantly increased the diversity of genomic data from

85 the group by adding transcriptomes from seven newly discovered species belonging to

86 Pirsoniales (Pirsonia chemainus nom. prov., Koktebelia satura nom. prov., and Feodosia

87 pseudopoda nom. prov.) and Developea (Develocanicus komovi n. gen. n. sp., Develocanicus

88 vyazemskyi n. sp., Develocauda condao n. gen. n. sp., and Cubaremonas variflagellatum n. gen.

89 n. sp.). The inferred 247-gene phylogenomic tree, reconstructed with various methods, recovered 
90 for the first time the monophyly of the Bigyromonadea. Maximum likelihood (ML) recovered a

91 robust monophyly of Bigyromonadea and oomycetes, while Bayesian inference and topology

92 testing were inconclusive. We describe several new features of the seven bigyromonads, and

93 noted their resemblance with oomycete zoospores, and report the first observation of

94 eukaryovory in the flagellated stages of Pirsoniales. Overall, these findings indicate

95 bigyromonada and ooymcetes are most likely sisters, and suggest potential ancestral state of the

96 oomycetes resembling bigyromonada, including their ability to form auto-aggregates (=self-

97 aggregates) (Galiana et al., 2008; Hickman, 1970; Ko and Chase, 1973) and phagoheterotrophy.

\section{Materials and Methods}

\subsection{Sample collection, identification, and library preparation}

Strain Colp-23 (Develocanicus komovi) was obtained from the black volcanic sand on the

102 littoral zone of Maria Jimenez Beach (Playa Maria Jiménez), Puerto de la Cruz, Tenerife, Spain,

103 October 20, 2014. Strains Colp-30 (Develocanicus vyazemskyi) and Chromo-1 (Koktebelia satura)

104 were isolated from the near shore sediments on the littoral zone near T.I. Vyazemsky Karadag

105 Scientific Station, Crimea, May 2015. Strain Chromo-2 (Feodosia pseudopoda) was obtained from

106 the near shore sand on the littoral zone of the beach in the settlement Beregovoye, Feodosiya,

107 Crimea, June 24, 2017. Strain Colp-29c (Develocauda condao) was isolated from the near shore

108 sediments on the north-east part of Con Dao Island, South Vietnam, May 4, 2015. Strains

109 'Pirsonia-like' (Pirsonia chemainus) and Dev-1 (Cubaremonas variflagellatum) were obtained

110 from a sea water samples taken in the Strait of Georgia, British Columbia, Canada $\left(123^{\circ} 28^{\prime} 50^{\prime \prime}\right.$

$111 \mathrm{~W}, 49^{\circ} 10^{\prime} 366^{\prime \prime} \mathrm{N}$ ) at $70 \mathrm{~m}$ and $220 \mathrm{~m}$ depths, respectively using a Niskin bottle, June 13, 2017. 
113 with methods described previously (Tikhonenkov et al., 2008). Procryptobia sorokini strain B-69

114 (IBIW RAS), feeding on Pseudomonas fluorescens, was cultivated in Schmaltz-Pratt's medium at

115 a final salinity of 20\%o, and used as a prey for clones Colp-23, Colp-29c, Colp-30, Chromo-1,

116 Chromo-2, and 'Pirsonia-like' (Tikhonenkov et al., 2014). Bacterivorous strain Dev-1 was

117 propagated on the Pseudomonas fluorescens, which was grown in Schmaltz-Pratt's medium.

118 Strains Colp-23, Colp-29c, and Dev-1 are currently being stored in a collection of live protozoan

119 cultures at the Institute for Biology of Inland Waters, Russian Academy of Sciences, however,

120 strains Colp-30, Chromo-1, Chromo-2, and 'Pirsonia-like' perished after several months to one

121 year of cultivation.

122 Studied isolates were identified using a combination of microscopic and molecular

123 approaches. Light microscopy observations were made using a Zeiss AxioScope A.1 equipped

124 with a DIC water immersion objective (63x) and an AVT HORN MC-1009/S analog video camera.

125 The SSU rRNA genes (GenBank accession numbers: XXXXXX, XXXX...) were amplified by

126 polymerase chain reaction (PCR) using the general eukaryotic primers EukA-EukB (for strains

127 Colp-23, Colp-30, 'Pirsonia-like’), PF1-FAD4 (Chromo-1), 18SFU-18SRU (Chromo-2, Dev-1),

128 25F-1801R (Colp-29c) (Cavalier-Smith et al., 2009; Keeling, 2002; Medlin et al., 1988;

129 Tikhonenkov et al., 2016). PCR products were subsequently cloned (Colp-23, Colp-30, Chromo-

130 2, 'Pirsonia-like') or sequenced directly (Chromo-1, Dev-1, Colp-29c) using Sanger dideoxy 131 sequencing.

For cDNA preparation, cells grown in clonal laboratory cultures were harvested when

133 the cells had reached peak abundance (strains Colp-23, Col-30, Colp29c, Chromo-1, Dev-1) and 134 after the majority of the prey had been eaten (for eukaryovorous strains Colp-23, Col-30, Colp29c, 
135 Chromo-1). Cells were collected by centrifugation (1000 x $g$, room temperature) onto the $0.8 \mu \mathrm{m}$

136 membrane of a Vivaclear mini column (Sartorium Stedim Biotech Gmng, Cat. No. VK01P042).

137 Total RNA was then extracted using a RNAqueous-Micro Kit (Invitrogen, Cat. No. AM1931) and

138 reverse transcribed into cDNA using the Smart-Seq2 protocol (Picelli et al., 2014), which uses

139 poly-A selection to enrich mRNA. Additionally, cDNA of Colp-29c was obtained from 20 single

140 cells using the Smart-Seq2 protocol (cells was manually picked from the culture using a glass

141 micropipette and transferred to a $0.2 \mathrm{~mL}$ thin-walled PCR tube containing $2 \mu \mathrm{L}$ of cell lysis buffer

$142-0.2 \%$ Triton X-100 and RNase inhibitor (Invitrogen)). The same 'single cell' transcriptomic

143 approach was applied for strains Chromo-2 and 'Pirsonia-like', which never consumed the prey

144 completely. Sequencing libraries were prepared using NexteraXT protocol and sequencing was

145 performed on an Illumina MiSeq using 300 bp paired-end reads. Additionally, Chromo-1

146 transcriptome sequencing was performed on the Illumina HiSeq platform (UCLA Clinical

147 Microarray Core) with read lengths of 100 bp using the KAPA stranded RNA-seq kit (Roche) to

148 construct paired-end libraries. Raw reads are available in the NCBI Short Read Archive (SRA)

149 (Bioproject number: XXXXXX, SRAXXX-XXX).

\subsection{Small-subunit phylogenetic tree reconstruction}

SSU rRNA sequences were identified from the seven new assembled transcriptomes

152 using Barrnap v0.9 (Seemann, 2007) and compared with the SSU sequences obtained with

153 Sanger sequencing, and the longer sequences were used for further analysis.

154 After an initial BLASTn search of the SSU rRNA sequences against the non-redundant

155 NCBI database to confirm stramenopile identities, the SSU sequences were aligned using

156 MAFFT v7.222 (Katoh and Standley, 2013) with previously compiled SSU datasets (Aleoshin et

157 al., 2016; Yubuki et al., 2015). Additionally, SSU sequences of the other stramenopile taxa that 
were included in the multi-gene phylogenomic dataset and other closely related taxa were included in Fig. 3. Furthermore, to show the diversity of uncultured Gyrista and provide possible directions for future sampling efforts, environmental sequences of stramenopiles that are closely

161 related to Pirsoniales and Developea were added in Fig. S4. After trimming using trimAl

162 v.1.2rev59 (-gt 0.3, -st 0.001) (Capella-Gutiérrez et al., 2009), the SSU phylogenetic trees were

163 reconstructed based on 1650 sites and 92 taxa for Fig. 3, and 1665 sites and 107 taxa for Fig. 4S,

164 using IQ-TREE v1.6.12 (Nguyen et al., 2015) 1000 ultrafast bootstrap (UFB) under Bayesian

165 information criterion (BIC): TIM2+R6 selected by ModelFinder (Kalyaanamoorthy et al., 2017)

166 implemented in IQ-TREE.

\subsection{Transcriptome processing, assembly, and decontamination} assembled using Trinity-v2.4.0 with -trimmomatic option to remove NexteraXT adaptors,

171 Smart-Seq2 IS-primer, and low quality leading and trailing ends (quality threshold cut-off:5)

172 (Bolger et al., 2014; Grabherr et al., 2011). To identify contaminants, assembled reads were 173 searched against the NCBI nucleotide database using megaBLAST (Basic Local Alignment

174 Search Tool) (Altschul et al., 1990), followed by diamond BLASTX against a UniProt reference

175 proteome (Bateman et al., 2021). To visualize the contig sizes, coverage, and remove bacterial,

176 archaeal, and metazoan contaminants, BlobTools v1.0 (Laetsch and Blaxter, 2017) was used.

177 PhyloFlash v3.3b2 (Gruber-Vodicka et al., 2020) was used in parallel to confirm identified

178 contaminants and coverage based on SILVA v138 SSU database (Quast et al., 2013). To remove

179 sequences from the prey, Procryptobia sorokini, which was used in the cultures of Pirsonia

180 chemainus, Koktebelia satura, Feodosia pseudopoda, Develocanicus komovi, D. vyazemskyi, and 
181 Develocauda condao, the assembled reads were searched against the $P$. sorokini transcriptome

182 using BLASTn in which the contigs with $\geq 95 \%$ sequence identity were removed from the

183 assembled reads. To predict open reading frames (ORFs) and coding genes, TransDecoder v5.5.0

184 (Haas, 2015) was used and the longest ORFs were annotated using BLASTP search against

185 UniProt database. To estimate the completeness of each of the assembly, BUSCO v4.0.5 (Simão

186 et al., 2015) with eukaryotic database was used.

\section{$187 \quad 2.4$ Phylogenomic matrix construction and ortholog identification}

To better represent each stramenopile (sub)group in the phylogenomic reconstruction, recently published and publicly available (Broad Institute and Japan Agency for Marine-Earth Science and Technology; JAMSTEC) additional 27 stramenopile genomic or transcriptome data

191 (de Vargas et al., 2015; Hackl et al., 2020; Keeling et al., 2014; Leonard et al., 2018; Noguchi et

192 al., 2016; Seeleuthner et al., 2018; Thakur et al., 2019; Wawrzyniak et al., 2015) were obtained

193 and analyzed along with the seven new transcriptomes (Table S1). The updated stramenopile

194 dataset including all the newly added transcriptomes in this study were compiled to the existing

195 gene-set described below. Using BLASTP, the predicted coding genes from each transcriptome

196 were searched against 263 gene-sets (orthologs), each consisting of compiled genes from major

197 supergroups of protists, fungi, and holozoans (Burki et al., 2016; Hehenberger et al., 2017). The

198 search results were filtered with an e-value threshold of 1e-20 with $>50 \%$ query coverage,

199 followed by read trimming based on UniProt search results. Each gene-set was aligned using

200 MAFFT-L-INS-i v.7222 and trimmed using trimAL v1.2rev59 (-gt 0.8). To identify orthologs

201 from the newly added transcriptomes aligned to the corresponding 263 gene-sets, 263 gene-trees

202 were built using Maximum-likelihood (ML) estimation with IQ-TREE v1.6.12 under the

203 LG+I+G4 model and 1000 ultrafast bootstrap (UFB) approximation. Each gene tree was 
manually screened in FigTree v1.4.4 and searched against BLAST nr-database for paralogs and contaminants (e.g., long branching sequences or sequences nested within bacterial, opisthokont and other distantly related clades), which were subsequently removed from each of the gene-set alignment. To increase ortholog coverage from the added transcriptomes, fragmented orthologs were manually combined only when the fragments were positioned in the same clade in a given gene tree, covered different regions of a gene, and if there was an overlapping region present,

210 permitting up to two mismatches. The 263 gene-sets containing the selected orthologs of the

211 newly added transcriptomes and 27 newly published stramenopile data were aligned using two

212 approaches and compared by reconstructing two phylogenomic trees. In the first approach

213 (approach 1), the sequences were aligned by using MAFFT L-INS-i v.7.222 and trimmed via

214 trimAL v1.2rev59 (-gt 0.8). In the second approach (approach 2), the sequences were filtered

215 using PREQUAL (Whelan et al., 2018) to remove non-homologous regions generated due to

216 poor transcriptome quality or assembly errors. The filtered sequences were then aligned using

217 MAFFT G-INS-i (--allowshift and --unalignlevel 0.6 option) and processed for further filtering 218 using Divvier (-mincol 4 and -divvygap option) (Ali et al., 2019) to identify statistically robust 219 pairwise homology characters. The filtered gene-sets were then soft-trimmed using trimAL (-gt

220 0.1). The two dataset generated by two different filtering and alignment methods were separately 221 processed using $\mathrm{SCaFoS}$ v1.2.5 (Roure et al., 2007), by removing gene-sets that have $\geq 40 \%$

222 missing amino acid positions in the alignment. The resulting 247 gene-set was concatenated into 223 a phylogenomic matrix comprising 75,798 amino acid (aa) sites from 76 taxa for approach 1. For

224 the PREQUAL/Divvier processed data (approach 2), the same 247 gene-sets were concatenated 225 in a phylogenomic matrix comprising 101,314 aa sites from the same 76 taxa.

\section{$226 \quad 2.5$ Phylogenomic tree reconstruction, fast-evolving site removal, and topology test}


The ML tree for the concatenated phylogenomic matrix was inferred using IQ-TREE

228 v.1.6.12 under the empirical profile mixture model, LG+C60+F+G4 (Quang et al., 2008). The

229 best tree under this model was used as a guide tree to estimate the "posterior mean site

230 frequencies" (PMSF). The PMSF method allows the conduction of non-parametric bootstrap

231 analyses under complex models on large data matrices and was shown to mitigate long-branch

232 attraction artifacts (Wang et al., 2018). This LG+C60+F+G-PMSF model was then used to re-

233 estimate the ML tree and for a non-parametric bootstrap analysis with 100 replicates. For

234 Bayesian inference, CAT-GTR mixture model with four gamma rate categories was used with 235 PhyloBayes-MPI v.20180420 (Lartillot et al., 2009; Lartillot and Philippe, 2004), only for the 236 dataset processed with approach 1. To estimate posterior probability, four independent Markov

237 Chain Monte Carlo (MCMC) chains were run simultaneously for minimum 10,000 cycles. After

238 discarding the first 2000 burn-in points, consensus posterior probability and topology were

239 computed by subsampling every second tree. Convergence of the four chains were tested by

240 calculating differences in bipartition frequencies (bpcomp) with a threshold maxdiff however, no

241 chains converged (maxdiff $=1)$.

242 Site-specific substitution rates were inferred using the -wsr option as implemented in IQ-

243 TREE, under the $\mathrm{LG}+\mathrm{C} 60+\mathrm{F}+\mathrm{G} 4$ substitution model. Increments of the top 5\% fastest evolving

244 sites were removed (Irwin, 2021) from the phylogenomic matrix until exhaustion, defined as the

245 point when the bootstrap support value significantly began to drop and the topology became

246 unstable $(50 \% ; 37,899$ sites $)$. Each incremental phylogenomic matrix was analyzed using IQ-

247 TREE for ML estimation using LG+C60+F+G4 and 1000 UFB. All fast-evolving species

248 removal and sites tests were conducted on the dataset processed with approach 1. 
Approximately unbiased (AU) tests (Nguyen et al., 2015; Shimodaira, 2002) were

250 performed on set of phylogenomic trees constructed based on the 247 gene-sets generated by the

251 first approach (i.e., MAFFT L-INS-i and trimAL with -gt 0.8) and the second approach (i.e.,

252 PREQUAL/Divvier), separately. The set of trees includes the two ML trees generated under

$253 \mathrm{LG}+\mathrm{C} 60+\mathrm{F}+\mathrm{G} 4(+\mathrm{PMSF})$ with 1000UFB (100STB), four consensus trees of MCMC chains, and

254 other hypothetical constrained trees as listed as "Chain modified" in Table 1.

255 3. Results

$256 \quad 3.1$ Multi-gene phylogenomic analysis

The concatenated phylogenomic matrix was composed of 68 stramenopiles and eight

258 alveolates (outgroup) with 247 aligned genes totaling 75,798 positions for approach 1, and

259101,314 positions for approach 2. The average missing sites and genes were $22 \%$ and $19 \%$,

260 respectively (Fig. 1). The amount of missing data varied among the seven new transcriptomes.

261 Chromo-1 had nearly complete data (5\% missing sites and 6\% missing genes) while Colp-29c

262 had $21 \%$ missing sites and 12\% missing genes. Colp-23 and Chromo-2 had the highest amount

263 of missing data (75\% missing sites and 57\% genes for Chromo-2 and, $83 \%$ and $76 \%$ for Colp-

264 23). The ML phylogenomic tree generated under $\mathrm{LG}+\mathrm{C} 60+\mathrm{F}+\mathrm{G} 4+\mathrm{PMSF}$ with STB estimation

265 from the two approaches is shown in Figure 1, with the tree topology representing the dataset

266 generated from approach 1 (i.e., MAFFT L-INS-i and trimAL with -gt 0.8). The tree topology

267 representing the dataset generated from approach 2 (i.e., Prequal/Divvier) is shown in Figure S1.

268 The tree topology is almost identical between the two, except the position of sub-clades in

269 ochrophytes; for example, the positions of Chrysophyceae + Synurophyceae and

270 Raphidophyceae + Phaeophyceae + Xanthophyceae + Eustigmatophaceae are swapped in the

271 two trees (Fig. 1; Fig. S1). 
273 monophyletic bigyromonada with either dataset (approach 1 and approach 2; Fig. 1; Fig. S1):

274 Develocanicus komovi, D. vyazemskyi, Develocauda condao, and Cubaremonas variflagellatum

275 forming a Developea clade (100\% STB), while Pirsoniales is composed of Pirsonia chemainus,

276 Koktebelia satura, and Feodosia pseudopoda (100\% STB). The ML tree also recovered

277 monophyly of the bigyromonada and oomycetes with $100 \%$ STB support (Fig. 1). The

278 monophyly of Gyrista was strongly supported, with Sagenista (Labyrinthulomycetes and

279 Eogyrea) forming a sister clade to it, resulting in a paraphyletic Bigyra. Platysulcea formed a

280 sister clade to rest of the stramenopiles with a moderate support (91\%/95\% STB) (Fig.1; Fig.

281 S1).

Bayesian analyses recovered a conflicting topology for the bigyromonada, which formed

283 a sister-clade to ochrophytes in all four consensus trees generated (Fig. S2). Additionally, the

284 topology within ochrophytes was inconsistent, preventing convergence. However, the

285 monophyly of bigyromonada + ochrophytes was rejected by approximately unbiased (AU) tests

286 in three of the four consensus trees. AU test failed to reject the chain 1 consensus tree at a

287 confidence interval of $95 \%$ (p-AU $\geq 0.05$ ) (Fig. S2). Interestingly, the sub-clade topology of

288 ochrophytes in chain 1 is the same as in the ML phylogenomic tree generated using the approach

2891 (Fig. 1; Fig. S2). When the AU tests were repeated on hypothetically constrained trees where

290 bigyromonada + oomycetes were monophyletic but the rest of the topology was unchanged for

291 each of the MCMC chains, the tests failed to reject the monophyly of bigyromonada +

292 oomycetes (Table 1). Rejection of bigyromonada + ochrophytes was also observed in

293 constrained trees when the AU test was repeated on the dataset processed with approach 2 (Table

294 S2). To evaluate the effect of fast-evolving sites, bootstrap support and topology were compared 
among the ML trees that were reconstructed with increments of 5\% fast-evolving sites removed from the dataset processed with approach 1 . The topologies of the phylogenomic tree were

298 possible artefacts due to long-branching attraction of fast-evolving species, tree reconstruction

299 was repeated after removing Cafeteria roenbergensis, the two Blastocystis species, and Cantina

300 marsupialis. The monophyly of bigyromonada and oomycetes was recovered with $85 \%$ UFB,

301 however the topology of Bigyra became unresolved with weak support for its monophyly (Fig.

302 S3)

$303 \quad 3.2$ Small-subunit ribosomal RNA gene tree reveals two different species assigned as

304 Developayella

As shown previously, the SSU rRNA phylogenetic tree recovered the bigyromonada as paraphyletic group, with the Pirsoniales (Pirsonia chemainus, Koktebelia satura, and Feodosia

307 pseudopoda) forming a sister clade to ochrophytes (92\% UFB) while the Developea clade was

308 recovered as sister to oomycetes (Fig. 3). Within the Developea clade, in addition to the SSU

309 rRNA sequences obtained from Cubaremonas variflagellatum and the JAMSTEC Developayella

310 elegans transcriptome, we included three publicly available SSU rRNA sequences assigned as

311 Developayella spp.: Accession ID U37107 (Leipe et al., 1996; Tong, 1995), MT355111.1

312 (Unpublished) and JX272636.1 (Del Campo et al., 2013): (note: although JX272636.1 is

313 assigned as “Cf. Developayella sp." in GenBank, it was recently re-assigned as Mediocremonas

314 mediterraneus (Weiler et al., 2020)). Interestingly, the SSU rRNA sequences of the four

315 "Developayella" fell into two separate groups, indicating two different species (and genera) were

316 assigned as Developayella elegans; sub-clade I consisted of Developayella elegans U37107,

317 Developayella sp. MT355111.1, Develocanicus komovi, D. vyazemskyi, and Develocauda 
condao, while sub-clade II consisted of M. mediterraneus (JX272636.1 and MT918788.1),

319 JAMSTEC Developayella elegans, and Cubaremonas variflagellatum (Fig. 3). The SSU rRNA

320 sequence similarity between the two sub-clade I Developayella species (U37107 and

321 MT355111.1) is 98.987\%, between the two species (JAMSTEC D. elegans and Cubaremonas

322 variflagellatum) in sub-clade II $97.528 \%$ and between the originally described Developayella

323 elegans U37107 and Cubaremonas variflagellatum $91.143 \%$.

\section{$324 \quad 3.3$ Morphology of the novel species}

Developea Karpov et Aleoshin 2016

Free-swimming naked eukaryovorous heterokont flagellates. The shape of the cell is irregularly flattened ellipse, where the dorsal side is more convex, and the ventral side is flatter.

Two species differ in size, Develocanicus vyazemskyi (Colp-30) is larger and rounder, 7.4 - 12.5 $\mu \mathrm{m}$ long, 4.8 - $9.2 \mu \mathrm{m}$ wide, typical dimension ranging 9.2 x $7.0 \mu \mathrm{m}$. Develocanicus komovi (Colp-

23 ) is slightly smaller, with the length $5.4-10 \mu \mathrm{m}$, width $3.8-7.4 \mu \mathrm{m}$ and a typical dimension of $7.1 \times 5.1 \mu \mathrm{m}$. approximately 1 - 1.5 times longer. Flagella emerge from a prominent ventral depression (Fig. 4AD) which passes into a shallow wide groove (Fig. 4E) along the entire length of the cell. Cells

338 posterior flagellum is directed backward and straight, running along the ventral depression of the 339 cell. The anterior flagellum beats rapidly and is directed forward while slightly curved. In non- 
The medial nucleus is located closer to the dorsal side of the cell (Fig. 4H). A large

342 digestive vacuole is situated at the posterior part of the cell (Fig. 4I, J). As it is digested, the

343 posterior end of the cell becomes thinner. The cells can form aggregations and attach to each other

344 (Fig. 4K), sometimes form pseudopodia (Fig. 4L). Transverse binary fission (Fig. 4M).

\section{Develocauda condao (Fig. 4N-W)}

Free-swimming eukaryovorous heterokont flagellates (Colp-29c). The cells are slightly

347 flattened, usually elongated-oval, less often narrow-oval or almost rod-shaped (Fig. 4Q). The

348 anterior end is more rounded, the posterior end of the cell can be pointed, forming a

349 characteristic "tail" found in starving cells (Fig. 4R, S). Cell length 5.14 - $12 \mu \mathrm{m}$, width 2.8 -

$350 \quad 5.42 \mu \mathrm{m}$ typically ranging $7.14 \times 4.28 \mu \mathrm{m}$ in dimension. The caudal extension is about $4.57 \mathrm{x}$

$351 \quad 1.42 \mu \mathrm{m}$ in size.

The cells have two heterodynamic flagella of an almost equal length with a posterior

353 flagellum compared to the cell body. Flagella emerge from a pronounced deep ventral depression

354 (Fig. 4N, O), which almost extends to the dorsal side of the cell. Depression transforms into a

355 shallow groove (Fig. 4P) spanning along the entire cell, in which the posterior flagellum can fit.

The cells swim very quickly without rotating along the longitudinal axis. The posterior

357 flagellum is straight and directed backwards. The anterior flagellum is directed forward, beats

358 actively, and is only slightly curved. Rarely, the cells lie at the bottom with both flagella directed

359 backward while making a slow sinusoidal movement, or the posterior flagellum beating actively.

360 The aggregated (Fig. 4U), partially fused cells (Fig. 4W) that form clusters were observed

361 in culture. The medial nucleus is located closer to the dorsal side of the cell. Sated cells do not

362 have a tail; at the posterior end of their cells there is a large digestive vacuole (Fig. 4T). Transverse 363 binary fission (Fig. 4V). 

width $2.6-5.4 \mu \mathrm{m}$, and the typical dimension of $5.0 \times 3.7 \mu \mathrm{m}$. The cell shape varies from elongated oval, oviform to rounder form (Fig. 4X-AA). Typically, the shape is irregularly ovoid,

368 with the convex dorsal side and the flatter ventral side. The shape and size vary depending on

369 feeding conditions. Starving cells have a small rostrum at the anterior end (Fig. 4AD). Cells are

$370 \quad$ larger before division.

373 continues ventrally to the middle of the cell. The anterior flagellum is approximately equal to the 374 cell length or slightly longer while the posterior flagellum is $1.5-1.8$ times longer than the cell.

375 Digestive vacuole is situated at the cell posterior. An observed cell division produces two or four 376 cells (Fig. 4AE).

In culture condition, the cells predominantly lie at the bottom unattached with both

378 flagella directed backward. The posterior flagellum runs along the ventral surface of the cell and beats rapidly with sinusoidal pattern to draw water through the depression. The anterior flagellum is hook-shaped and sweeps slowly down behind the posterior flagellum. 

as a flattened oval, with slightly pointed ends with the size $10.5-14 \mu \mathrm{m}$ in length, $6-9.1 \mu \mathrm{m}$ in width, and typically having the dimension of $12 \times 8.2 \mu \mathrm{m}$. The flagellated stages of three studied Pirsoniales were almost morphologically identical except Feodosia pseudopoda (Chromo-2) which possesses small notch at the anterior part of the cell (Fig. 4AF, AG). Rarely, F. pseudopoda can produce pseudopodia (Fig. 4AM, AN), which are up to $10 \mu \mathrm{m}$ long and sometimes branched. of the cell (Fig. 4AL, AM, AO). The length of the anterior flagellum is as long as the cell, while the posterior one is 2.5 times longer.

The cells swim fast in a straight line, without rotating along the longitudinal axis. The anterior flagellum is directed anteriorly, always bent towards the ventral surface. The posterior (Fig. 4AI). In stationary cells, the flagella take the form of a sinusoid (Fig. 4AJ, AK). refractive granules as observed in previously described Pirsonia species (Schweikert and Schnepf, 1997). Non-flagellated cells were also observed with slightly amoeboid and round shape (Fig. 4AP-AR). The satiated cells have a large digestive vacuole at the posterior end (Fig. 4AS). The eukaryovory of the biflagellates seems to be facultative as the most did not actively pursue the prey but only Koktebelia satura (clone Chromo-1) consumed all the prey cells in culture.

\section{Discussion}




\subsection{Monophyly and Phylogenetic Position of the Bigyromonadea}

Of the known subdivisions of stramenopiles, the Bigyromonadea stand out for their lack

412 of data and contentious position in the tree (even the newly discovered P. tardus is represented

413 by transcriptomic data and consistency branches at the base of the tree). From the five recent

414 phylogenomic analyses of stramenopiles, only three included a single bigyromonada

415 representative (D. elegans JAMSTEC), none tested the monophyly of the group, and they

416 recovered inconsistent positions. Using transcriptomes of seven new species belonging to the

417 Bigyromonadea representing both the Developea and Pirsoniales subgroups, we tested the

418 monophyly of the group and its position relative to other stramenopiles.

Previously, only SSU rRNA phylogenies could be used to test the monophyly of the

420 Bigyromonadea, and such analyses consistently failed to support the monophyly, typically

421 showing Developea with oomycetes and Pirsoniales with ochrophytes (Aleoshin et al., 2016;

422 Kühn et al., 2004; Weiler et al., 2020). In contrast, phylogenomic data consistently and strongly

423 supports the monophyly of these two groups, and shows each to include multiple distinct genera.

424 The position of Bigyromonadea within stramenopiles as a whole is also contentious, with

425 some analyses showing the previously available transcriptome from D. elegans branching with

426 oomycetes (Noguchi et al., 2016; Thakur et al., 2019), and based on internode consistency

427 analyses (Kobert et al., 2016; Leonard et al., 2018, with ochrophytes). This discrepancy is not

428 entirely eliminated by the addition of new taxa, since ML phylogenomic trees with the expanded

429 representation recovered monophyly of the bigyromonada and oomycetes with robust support,

430 but Bayesian analyses show a monophyly of bigyromonada+ochrophytes, and AU tests rejected

431 most but not all topologies with this relationship (Table 1; Table S2). 
433 (Chrysista and Bigyromonadea) that do not fit the same model for tree reconstruction. Although

434 it is not the aim of this study to resolve the phylogeny of ochrophytes, further examination of

435 ochrophyte phylogeny, may reveal whether the discrepancy stems from the unreconciled model

436 used in the two groups, the different data processing approaches used, or insufficient data in one

437 or both groups.

These results change how we interpret these lineages and their biological characteristics

439 within the wider evolution of stramenopiles. For example, the phylogenetic position of

440 Pirsoniales inferred from ribosomal genes showed they share a recent common ancestor with the

441 ochrophytes, which naturally affected the interpretation of the ancestral state of ochrophytes and

442 the role of phagoheterotrophy in their evolution (Aleoshin et al., 2016; Shiratori et al., 2017).

443 However, the phylogenomic tree points instead to a phagoheterotrophic origin of the

444 Pseudofungi. Parallels between this and recent suggestions on the origin of fungi are noteworthy,

445 since Paraphelidium tribonemae, a phagoheterotrophic parasite belonging to phylum Aphelida,

446 has recently been found to be sister to the osmotrophic "core" fungi by phylogenomics (Torruella

447 et al., 2018). Close similarities in metabolism and a phagotrophy-related proteome profile of $P$.

448 tribonemae and the osmotrophic "core" fungi suggested the "core" fungi have evolved from a

449 phagoheterotrophic aphelid-like ancestor. Further information on the metabolism and feeding

450 mechanisms of the new species should shed light on whether the origins of fungi and

451 pseudofungi have more parallels and on the possible phagoheterotrophic ancestral state of

452 Gyrista more widely.

453 Of course, this is also dependent on conclusively determining the position of

454 Bigyromonadea. Substantial advances in phylogenetic methods have been made, but challenges 
stemming from systematic errors, compositional bias, or long branch attraction, incomplete or contaminated data, and models that do not account for heterotachy in large datasets (Delsuc et

457 al., 2005; Kapli et al., 2020; Zhou et al., 2007) remain. Similarly, advances in single-cell

458 sequencing have vastly increased the taxonomic scope of phylogenomics, but the severely

459 limited starting material and the fact that they are by definition a snapshot of gene expression in

460 one cell remain important hurdles. Here, the removal of fast-evolving sites (Fig. 2), species (Fig.

461 S3), extensive AU test (Table 1;Table S2;Fig. S2) and two different data processing approaches

462 collectively tip the scale in favour of the monophyly of bigyromonada and oomycetes over the

463 alternative position of bigyromonada with ochrophytes. However, the conflicting results of

464 Bayesian inferences show that the lack of a robust phylogenomic tree was not just due to lack of

465 taxonomic diversity. Continued sampling efforts in phagoheterotrophic stramenopiles will

466 expand the phylogenetic diversity of the Bigyromonadea (and environmental SSU rRNA data

467 already show there are more new taxa to be found), but other advances in data generation and 468 analyses will also be required.

$469 \quad 4.2$ Morphology, evolutionary implications, and taxonomic description of the novel

470 phagoheterotrophic Bigyromonadea

472 cell-aggregation to fusion, pseudopod-formation, and facultative phagotrophy in motile

473 zoospores

474 Before we compare morphological features, we need to clarify that the JAMSTEC strain

475 of Developayella elegans has been mis-named and is a distinct species in a different genus.

476 According to the SSU rRNA gene tree (Fig. 3), the originally described D. elegans U37107

477 (Tong, 1995), is only distantly related to D. elegans JAMSTEC, and placed in distinct sub-clade 
478 of Developea where it is most closely related to C. variflagellatum. Renaming D. elegans

479 JAMSTEC will be necessary in the future: its close relatedness to Cubaremonas is sufficient to

480 say it is mis-named, but rectifying this should take into account morphological information,

481 which is currently unavailable. Overall, however, the novel developeans have similar

482 morphological traits as previously described species. For example, C. variflagellatum falls in the

483 same sub-clade as Mediocremonas mediterraneus (Del Campo et al., 2013; Weiler et al., 2020)

484 (Fig. 3), and both have similar morphology. C. variflagellatum is slightly larger, but

485 measurements for $M$. mediterraneus $(2.0-4.0 \mu \mathrm{m}$ in length and $1.2-3.7 \mu \mathrm{m}$ in width) were most

486 likely based on scanning electron microscopy (SEM) images and cells tend to shrink in SEM

487 fixatives (Weiler et al., 2020). The cell size, flagella length and swimming movement of $C$.

488 variflagellatum exhibited close similarity to D. elegans U37107, which was named after its

489 characteristic developpé movement of the anterior flagellum during stationary feeding (Tong,

490 1995). However, no thread-like substances were observed, which D. elegans uses to attach to

491 substrate.

492 The remaining novel Developea species, Develocanicus vyazemskyi, D. komovi, and

493 Develocauda condao, differed from D. elegans JAMSTEC and C. variflagellatum by having a

494 proportionately longer posterior flagellum, forward propulsion without rotating its axis, a

495 eukaryovorous diet (like Develorapax marinus (Aleoshin et al., 2016)), and the presence of a

496 "tail" in D. condao. Notably, the ability of the cells to form aggregates (Fig. 4K, U), pseudopodia

497 (Fig. 4L), and to undergo partial cell fusion (Fig. 4W) has not been reported in this clade

498 previously. The above-mentioned differences between $D$. vyazemskyi D. komovi, Develocauda

499 condao, and C. variflagellatum are also phylogenetically reflected in the division of these species

500 into two sub-clades (Fig. 1; Fig. 3). 
502 chemainus, described here as nomen provisorium, most likely represent a motile zoospore stage

503 of unknown algal parasites. The novel Pirsoniales species did not actively pursue the provided

504 prey and only partially consumed their prey (except $K$. satura which consumed all the prey

505 provided), all the cultures died after a few months to one year of cultivation. Although there has

506 been extensive description of auxosome and trophosome formation during the parasitic stage of

507 known Pirsoniales (Schnepf et al., 1990; Schweikert and Schnepf, 1997), the ability of motile

508 zoospores to acquire effective eukaryovory has not been described so far. The observed

509 eukaryovory of the zoospore-like Pirsoniales is likely facultative, as the cells were cultured

510 without potential hosts and the cells with larger food vacuoles became non-flagellated and

511 rounded, a structure akin to an auxosome. However, further culture experimentations with their

512 natural hosts are required to verify their ability to form parasitic auxosomes and trophosomes

513 from motile phagotrophic zoospores.

514 We postulate that the facultative eukaryovory at the motile zoospore stage provides a

515 significantly increased survival rate and thus extension of the motile stage during their dispersal

516 until a suitable host is found. This ability can be particularly advantageous before the onset of

517 seasonal algal bloom, where the zoospores can efficiently infect multiple hosts without resource

518 competition. Therefore, the sustained survival of the zoospores via facultative eukaryovory could

519 be an important factor leading to the evolutionary success of Pirsoniales parasites.

$520 \quad$ Feodosia pseudopoda differed from rest of the Pirsoniales studied here by an anterior

521 notch (Fig. AF, AG) and rare occurrences of pseudopodia (Fig. AM-AO). Interestingly, the two

522 characteristics have been reported in Pseudopirsonia mucosa, a cercomonad rhizarian (Kühn et

523 al., 2004), which had been mis-assigned as Pirsonia due to the similarities in their parasitic life 
524 cycles. In starving and immobile zoospores of Pirsonia puntigerae, filopodium-like processes

525 (Schweikert and Schnepf, 1997) have been described however, pseudopodia in motile zoospores

526 of Pirsoniales have not been observed previously.

527 The presence of pseudopodia, and the ability to form aggregated cells in the newly

528 described sub-clade I of Developea and previously reported publications of Pirsoniales may

529 indicate synapomorphic traits of Bigyromonadea. It will be important for future studies to

530 compare ultrastructure and genes putatively associated with cell-aggregation or fusion among the

531 species of bigyromonada, thus potentially addressing the evolution of an osmotrophic nutritional

532 strategy in stramenopiles.

533 4.2.2 Similarities among Oomycetes motile zoospores, Labyrinthulomycetes, and

534 Bigyromonadea

535 Morphologically, the novel Developea species have similar features as motile zoospores

536 of previously studied oomycetes, such as the general cell dimension, the proportion between

537 anterior and posterior flagellum, and two laterally oriented flagella (with a tinsellate anterior

538 flagellum) emerging from a ventral groove (Dick, 2000), which resembles the ventral depression

539 observed in the novel species. Behaviourally, the swimming pattern (e.g., direction of flagella,

540 sinusoid form) is comparable (Hickman, 1970; Ho and Hickman, 1967). Another striking

541 similarity between the two groups is their ability to self-aggregate, which is observed in

542 oomycete zoospores as a distinct form of self-aggregation compared to aggregation towards host-

543 plant tissues (Bassani et al., 2020; Ko and Chase, 1973). The mechanism underlying self-

544 aggregation in oomycetes has not been fully resolved, however recent studies suggest that a

545 combination of chemotaxis (Bassani et al., 2020; Judelson and Blanco, 2005; Zheng and

546 Mackrill, 2016) and bioconvection (Savory et al., 2014), is involved in the process. The exact 
547 role of the self-aggregation in oomycete pathogenesis is still unclear, however the fact that a

548 similar observation was made in its sister-clade, the Bigyromonadea, indicates that self-

549 aggregation may have been present in the ancestor of Pseudofungi, before the osmotrophic

550 parasitism of oomycetes evolved. Cell aggregation is also observed in Sorodiplophrys (Dykstra

551 et al., 1975), a species belonging to another osmotrophic group of stramenopiles, the

552 labyrinthulomycetes. Cell aggregation has convergently evolved multiple times across many

553 other supergroups (Parfrey and Lahr, 2013), such as Amoebozoa (Du et al., 2015), Rhizaria

554 (Brown et al., 2012), and ciliates (Sugimoto and Endoh, 2006), and whether cell aggregation

555 within stramenopiles arose convergently or divergently should be further investigated.

As mentioned previously, some species described in this study formed pseudopodia (Fig.

557 4L,4AM,4AN) and partially fused cells (Fig. 4W) resembling amoeboid forms. Interestingly,

558 labyrinthulomycetes also form filose pseudopodia (Gomaa et al., 2013) akin to pseudopodia

559 observed in this study (Fig. 4AM, AN). These are found in Amphitremidae, during an amoeboid

560 stage of Diplophrys (Anderson and Cavalier-Smith, 2012), and other labyrinthulids

561 (Raghukumar, 1992), implying this trait either evolved convergently or was present earlier than

562 the divergence of Pseudofungi.

Another notable similarity between oomycetes and the novel bigyromonada is their

564 potential marine origin, as all known bigyromonads are exclusively marine. Molecular clock

565 analyses indicate the Silurian period as the time of oomycete origins (Matari and Blair, 2014),

566 while the earliest fossil evidence points to the Devonian period (Krings et al., 2011). The fossil

567 evidence of the early diverging genera have shown them to be marine parasites of seaweed, or

568 of crustaceans based on molecular studies (Beakes and Sekimoto, 2009), both suggesting a 
marine origin of oomycetes as a facultative parasitic osmotroph (Beakes et al., 2014, 2012;

570

571

572

573

574

575

576

577

evolution of these unique phagoheterotrophs and oomycetes.

Beakes and Thines, 2017).

The origin and evolution of major stramenopile subgroups is coming into sharper focus

with the increase in phylogenomic data from diverse species. The new taxa described here,

together with future descriptions of the still-substantial diversity of bigyromonada that has not

been well-characterized, can potentially shed more light on this and the origins of oomycetes in particular. We propose that the ancestor of oomycetes was a phagoheterotrophic amoeboid, as

postulated in the evolution of true fungi (Zmitrovich, 2018), and that this transition might be better understood through a detailed functional examination of the novel species. Just as the highly successful analyses of choanoflagellates and unicellular opisthokonts changed our understanding of the origin of animals (Chow et al., 2019; Sebé-Pedrós et al., 2013), a similar analysis of the distribution of genes involved in Pseudofungi cell-aggregation or pseudopodia formation across the diversity of bigyromonads could be a future direction to understand the

TAXONOMIC SUMMARY

586 Taxonomy: Eukaryota; SAR Burki et al. 2008, emend. Adl et al. 2012; Stramenopiles Patterson

587 1989, emend. Adl et al. 2005; Gyrista Cavalier-Smith 1998; Bigyromonadea Cavalier-Smith, T.

588 1998; Developea Karpov et Aleoshin 2016 Cubaremonas n. gen. Tikhonenkov, Cho, and

$589 \quad$ Keeling

590 Diagnosis: naked and solitary bacteriovorous protist. Cell shape is irregularly ovoid, with the 591 convex dorsal side and the flatter ventral side. Cells possess two heterodynamic flagella 
emerging from a conspicuous ventral depression, which starts from the anterior end and

593 continues ventrally to the middle of the cell. In culture condition, the cells predominantly lie at

594 the bottom unattached with both flagella directed backward.

595 Etymology: from lat. cubare - to lie, to be lying down and monas (lat.) - unicellular organism.

596 Zoobank Registration. urn:1sid:zoobank.org:act:xxxxx

597 Type species. Cubaremonas variflagellatum

598 Cubaremonas variflagellatum n. sp. Tikhonenkov, Cho, and Keeling

599 Diagnosis: cells length $3.7-8 \mu \mathrm{m}$, cell width $2.6-5.4 \mu \mathrm{m}$. Flagella of unequal length, the

600 anterior one is approximately equal to the cell length while the posterior flagellum is $1.5-1.8$

601 times longer than the cell. At lying cells, posterior flagellum runs along the ventral surface of the

602 cell and beats rapidly with sinusoidal pattern to draw water through the depression. The anterior

603 flagellum is hook-shaped and sweeps slowly down behind the posterior flagellum. Starving cells

604 have a small rostrum at the anterior end. Digestive vacuole is situated at the cell posterior. An

605 observed cell division produces two or four cells.

606 Type Figure: Fig. 4X illustrates a live cell of strain Dev-1.

607 Gene sequence: The SSU rRNA gene sequence has the GenBank Accession Number XXXXX.

608 Type locality: water column of Strait of Georgia, British Columbia, Canada

609 Etymology: the species name means "unequal flagella", lat.

610 Zoobank Registration: urn:lsid:zoobank.org:act:XXXXXXXX

611

612 Develocanicus n. gen. Tikhonenkov, Cho, Mylnikov, and Keeling 
613 Diagnosis: Free-swimming naked eukaryovorous heterokont flagellates with two non-

614 acronematic heterodynamic flagella of unequal lengths. The shape of the cell is irregularly

615 flattened ellipse, where the dorsal side is more convex, and the ventral side is flatter. Flagella

616 emerge from a prominent ventral depression which passes into a shallow wide groove along the

617 entire length of the cell.

618 Etymology: from développé (fr.) - characteristic ballet movement and volcanicus (lat.) (found

619 near volcanos in Kanary island and Crimea).

620 Zoobank Registration. urn:1sid:zoobank.org:act:Xxxxx

621 Type species. Develocanicus komovi

623 Develocanicus komovi n. sp. Tikhonenkov, Cho, Mylnikov, and Keeling

624 Diagnosis: cell length $5.4-10 \mu \mathrm{m}$, cell width $3.8-7.4 \mu \mathrm{m}$. The posterior flagellum is two times

625 longer than the cell, the anterior flagellum is approximately $1-1.5$ times longer. Cells swim

626 without rotation. At that, posterior flagellum is directed backward and straight, running along the

627 ventral cell of the cell. Anterior flagellum beats rapidly and is directed forward while slightly

628 curved. Medial nucleus is located closer to the dorsal side of the cell. Large digestive vacuole is

629 situated at the posterior part of the cell. Cells can form pseudopodia and aggregations and attach

630 to each other. Transverse binary fission.

631 Type Figure: Fig. 4C illustrates a live cell of strain Colp-23.

632 Gene sequence: The SSU rRNA gene sequence has the GenBank Accession Number XXXXX.

633 Type locality: black volcanic sand on the littoral of Maria Jimenez Beach (Playa Maria Jiménez),

634 Puerto de la Cruz, Tenerife, Spain 
635 Etymology: named after Prof., Dr. Viktor T. Komov, Russian ecotoxicologist, who carried out

636 fieldwork and collect samples, where new species was discovered.

637 Zoobank Registration: urn:lsid:zoobank.org:act:XXXXXXXX

639 Develocanicus vyazemskyi n. sp. Tikhonenkov, Cho, Mylnikov, and Keeling

640 Diagnosis: cell 7.4 - $12.5 \mu \mathrm{m}$ long, 4.8 - 9.2 $\mu \mathrm{m}$ wide. The posterior flagellum is two times

641 longer than the cell, the anterior flagellum is approximately $1-1.5$ times longer. Cells swim

642 without rotation. At that, posterior flagellum is directed backward and straight, running along the

643 ventral cell of the cell. Anterior flagellum beats rapidly and is directed forward while slightly

644 curved. In non-motile cells, both flagella are directed backward, beating in a slow sinusoidal

645 wave. Medial nucleus is located closer to the dorsal side of the cell. Large digestive vacuole is

646 situated at the posterior part of the cell. Transverse binary fission.

647 Type Figure: Fig. 4A illustrates a live cell of strain Colp-30.

648 Gene sequence: The SSU rRNA gene sequence has the GenBank Accession Number XXXXX.

649 Type locality: near shore sediments on the littoral near T.I. Vyazemsky Karadag Scientific

650 Station, Crimea

651 Etymology: named after Dr. T.I. Vyazemsky, founder and first director of Karadag Scientific

652 Station, Crimea

653 Zoobank Registration: urn:lsid:zoobank.org:act:XXXXXXXX

655 Develocauda n. gen. Tikhonenkov, Cho, and Keeling 
656 Diagnosis: Free-swimming eukaryovorous heterokont flagellates with slightly flattened

657 elongated-oval cells and two heterodynamic flagella. The anterior end is more rounded, the

658 posterior end of the cell can be pointed, forming a characteristic "tail" in starving cells. Flagella

659 emerge from a pronounced deep ventral depression, which almost extends to the dorsal side of

660 the cell. Depression transforms into a shallow groove spanning along the entire cell, in which the

661 posterior flagellum can fit.

662 Etymology: from développé (fr.) - characteristic ballet movement and cauda (lat.) - tail.

663 Zoobank Registration. urn:1sid:zoobank.org:act:xxxxx

664 Type species. Develocauda condao

667 Develocauda condao n. sp. Tikhonenkov, Cho, and Keeling

668 Cell length $5.14-12 \mu \mathrm{m}$, width $2.8-5.42 \mu \mathrm{m}$. The caudal extension is about $4.57 \times 1.42 \mu \mathrm{m}$ in

669 size. Flagella of almost equal length. The cells swim very quickly without rotating along the

670 longitudinal axis. The posterior flagellum is straight and directed backwards. The anterior

671 flagellum is directed forward, beats actively, and is only slightly curved. Cells can be partially

672 fused and aggregated. Medial nucleus is located closer to the dorsal side of the cell. Transverse

673 binary fission.

674 Type Figure: Fig. 4N illustrates a live cell of strain Colp-29.

675 Gene sequence: The SSU rRNA gene sequence has the GenBank Accession Number XXXXX.

676 Type locality: near shore sediments on the littoral of north-east part of Con Dao Island, South

677 Vietnam

678 Etymology: named after Con Dao Island, South Vietnam, where species was discovered. 
681 Pirsoniales Cavalier-Smith 1998, emend. 2006

682 Studied pirsoniales most likely represent a motile zoospore stages of unknown algal parasites.

683 Since data on the stage of the parasitic trophonts (auxosome and a trophosome) are not available,

684 it is premature to formulate taxonomic diagnoses. But we provide provisional names (nom.

685 prov.) which can be used for future research.

686 Pirsonia chemainus nom. prov. Tikhonenkov, Cho, and Keeling

687 Etymology: species epithet is after the Stz'uminus First Nation traditional territory (Strait of

688 Georgia area) claimed by the Chemainus First Nation

689 Type locality: water column of the Strait of Georgia, British Columbia, Canada

690 Gene sequence: The SSU rRNA gene sequence has the GenBank Accession Number XXXXX.

691 Koktebelia satura nom. prov. Tikhonenkov, Cho, and Keeling

692 Etymology: genus epithet reflects the place of finding, Koktebel bay, Crimea; species epithet -

693 from satur (lat.), well-fed.

694 Type locality: near shore sediments on the littoral near T.I. Vyazemsky Karadag Scientific

695 Station, Crimea

696 Gene sequence: The SSU rRNA gene sequence has the GenBank Accession Number XXXXX.

698 Feodosia pseudopoda nom. prov. Tikhonenkov, Cho, and Keeling

699 Etymology: genus epithet reflects the place of finding, the settlement Beregovoye, Feodosiya,

700 Crimea; species epithet reflects the ability to produce pseudopodia. 
bioRxiv preprint doi: https://doi.org/10.1101/2021.11.17.469027; this version posted November 19,2021 . The copyright holder for this preprint (which was not certified by peer review) is the author/funder, who has granted bioRxiv a license to display the preprint in perpetuity. It is made available under aCC-BY-NC-ND 4.0 International license.

701 Type locality: near shore sand on the littoral of the beach in the settlement Beregovoye,

702 Feodosiya, Crimea

703 Gene sequence: The SSU rRNA gene sequence has the GenBank Accession Number XXXXX. 


\section{Acknowledgements}

707 We thank Dr. Viktor Komov (IBIW RAS), Larysa Pakhomova (UBC), Dr. Evgeny Gusev (IPP

708 RAS) for helping with the sample collection in the Canary Islands, Strait of Georgia (British

709 Columbia), and Vietnam as well as Dmitry Zagumyonnyi (IBIW RAS) for the help with

710 Pirsoniales photography. Field work in Vietnam is part of the project 'Ecolan 3.2' of the

711 Russian-Vietnam Tropical Centre. This work was supported by the Russian Science Foundation

712 grant no. 18-14-00239, https://rscf.ru/project/18-14-00239/ (cell isolation and culturing,

713 microscopy, SSU rRNA sequencing, and analyses), NSERC Grant 2014- 03994 to PJK

714 (sequencing and bioinformatics), and NSERC Postgraduate Scholarship-Doctoral (PGSD) and

715 University of British Columbia Botany Four-Year Fellowship to AC. 


\section{References}

717 Aleoshin, V. V., Mylnikov, A.P., Mirzaeva, G.S., Mikhailov, K. V., Karpov, S.A., 2016. Heterokont predator Develorapax marinus gen. et sp. nov. - A model of the ochrophyte

Ali, R.H., Bogusz, M., Whelan, S., Tamura, K., 2019. Identifying Clusters of High Confidence Homologies in Multiple Sequence Alignments. Mol. Biol. Evol. 36, 2340-2351.

Altschul, S.F., Gish, W., Miller, W., Myers, E.W., Lipman, D.J., 1990. Basic Local Alignment Search Tool. J. Mol. Biol. 215, 403-410. https://doi.org/10.1016/S0022-2836(05)80360-2

Anderson, O.R., Cavalier-Smith, T., 2012. Ultrastructure of Diplophrys parva, a new small freshwater species, and a revised analysis of Labyrinthulea (Heterokonta). Acta Protozool.

Andrews, S., 2010. FastQC: A quality control tool for high throughput sequence data. of k+-induced aggregation in phytophthora parasitica zoospores. Microorganisms 8, 1-18. Ishtiaq, R., Jokinen, P., Joshi, V., Jyothi, D., Lock, A., Lopez, R., Luciani, A., Luo, J., Lussi, Y., MacDougall, A., Madeira, F., Mahmoudy, M., Menchi, M., Mishra, A., Moulang, 
K., Nightingale, A., Oliveira, C.S., Pundir, S., Qi, G., Raj, S., Rice, D., Lopez, M.R., Saidi,

Feuermann, M., Gasteiger, E., Gehant, S., Gerritsen, V., Gos, A., Gruaz-Gumowski, N.,

Beakes, G.W., Glockling, S.L., Sekimoto, S., 2012. The evolutionary phylogeny of the oomycete

Beakes, G.W., Honda, D., Thines, M., 2014. Systematics of the Straminipila:

Beakes, G.W., Sekimoto, S., 2009. The evolutionary phylogeny of oomycetes - insights gained 
(Eds.), Oomycete Genetics and Genomics: Diversity, Interactions, and Research Tools.

John Wiley \& Sons, Inc, USA, pp. 1-24. https://doi.org/10.1002/9780470475898.ch1

Beakes, G.W., Thines, M., 2017. Hyphochytriomycota and Oomycota., in: Archibald, J.M.,

Bendtsen, J.D., Nielsen, H., Von Heijne, G., Brunak, S., 2004. Improved prediction of signal peptides: SignalP 3.0. J. Mol. Biol. 340, 783-795. https://doi.org/10.1016/j.jmb.2004.05.028

Bessey, E.A., 1950. Hyphochytriales, in: Morphology and Taxonomy of Fungi. The Blakiston Company, Philadelphia, PA, USA, p. 675.

Bolger, A.M., Lohse, M., Usadel, B., 2014. Trimmomatic: A flexible trimmer for Illumina sequence data. Bioinformatics 30, 2114-2120. https://doi.org/10.1093/bioinformatics/btu170

Brown, M.W., Kolisko, M., Silberman, J.D., Roger, A.J., 2012. Aggregative multicellularity evolved independently in the eukaryotic supergroup Rhizaria. Curr. Biol. 22, 1123-1127.

Burki, F., Kaplan, M., Tikhonenkov, D. V., Zlatogursky, V., Minh, B.Q., Radaykina, L. V., Smirnov, A., Mylnikov, A.P., Keeling, P.J., 2016. Untangling the early diversification of eukaryotes: A phylogenomic study of the evolutionary origins of centrohelida, haptophyta and cryptista. Proc. R. Soc. B Biol. Sci. 283. https://doi.org/10.1098/rspb.2015.2802 
Cavalier-Smith, T., 1998. A revised six-kingdom system of life. Biol. Rev. Camb. Philos. Soc.

787 Cavalier-Smith, T., Chao, E.E.Y., 2006. Phylogeny and megasystematics of phagotrophic heterokonts (kingdom Chromista). J. Mol. Evol. 62, 388-420. https://doi.org/10.1007/s00239-004-0353-8

Cavalier-Smith, T., Lewis, R., Chao, E.E., Oates, B., Bass, D., 2009. Helkesimastix marina n. sp. (Cercozoa: Sainouroidea superfam. n.) a Gliding Zooflagellate of Novel Ultrastructure and Unusual Ciliary Behaviour. Protist 160, 452-479. https://doi.org/10.1016/j.protis.2009.03.003

Cavalier-Smith, T., Scoble, J.M., 2013a. Phylogeny of Heterokonta: Incisomonas marina, a

Cavalier-Smith, T., Scoble, J.M., 2013b. Phylogeny of Heterokonta: Incisomonas marina, a uniciliate gliding opalozoan related to Solenicola (Nanomonadea), and evidence that Actinophryida evolved from raphidophytes. Eur. J. Protistol. 49, 328-353. https://doi.org/10.1016/j.ejop.2012.09.002 C., Le Bescot, N., Probert, I., Carmichael, M., Poulain, J., Romac, S., Colin, S., Aury, J.-M., Bittner, L., Chaffron, S., Dunthorn, M., Engelen, S., Flegontova, O., Guidi, L., Horak, A., 
Jaillon, O., Lima-Mendez, G., Lukes, J., Malviya, S., Morard, R., Mulot, M., Scalco, E.,

Siano, R., Vincent, F., Zingone, A., Dimier, C., Coordinators, T.O., Picheral, M., Searson,

S., Kandels-Lewis, S., Acinas, S.G., Bork, P., Bowler, C., Gorsky, G., Grimsley, N.,

Hingamp, P., Iudicone, D., Not, F., Ogata, H., Pesant, S., Raes, J., Sieracki, M.E., Speich, https://doi.org/10.1126/science.1261605

Del Campo, J., Not, F., Forn, I., Sieracki, M.E., Massana, R., 2013. Taming the smallest predators of the oceans. ISME J. 7, 351-358. https://doi.org/10.1038/ismej.2012.85

Delsuc, F., Brinkmann, H., Philippe, H., 2005. Phylogenomics and the reconstruction of the tree of life. Nat. Rev. Genet. 6, 361-375. https://doi.org/10.1038/nrg1603

Derelle, R., López-García, P., Timpano, H., Moreira, D., 2016. A Phylogenomic Framework to Study the Diversity and Evolution of Stramenopiles (=Heterokonts). Mol. Biol. Evol. 33, 2890-2898. https://doi.org/10.1093/molbev/msw168

Dick, M.W., 2000. Straminipilous fungi: systematics of the peronosporomycetes, including

Du, Q., Kawabe, Y., Schilde, C., Chen, Z.H., Schaap, P., 2015. The Evolution of Aggregative Multicellularity and Cell-Cell Communication in the Dictyostelia. J. Mol. Biol. 427, 37223733. https://doi.org/10.1016/j.jmb.2015.08.008 accounts of the marine straminipilous portests, the plasmodiophorids, and similar organisms, 1st ed. Spring Netherlands, Netherlands. https://doi.org/10.1007/978-94-0159733-3

Dykstra, M.J., Olive, L.S., Mycologia, S., Aug, J., Aug, N.J., Dykstra, M.J., Olive, L.S., 1975. 
https://doi.org/10.2307/3758346

832 Galiana, E., Fourré, S., Engler, G., 2008. Phytophthora parasitica biofilm formation: Installation and organization of microcolonies on the surface of a host plant. Environ. Microbiol. 10,

Gomaa, F., Mitchell, E.A.D., Lara, E., 2013. Amphitremida (Poche, 1913) Is a New Major, Ubiquitous Labyrinthulomycete Clade. PLoS One 8. https://doi.org/10.1371/journal.pone.0053046

Grabherr, M.G., Haas, B.J., Yassour, M., Levin, J.Z., Thompson, D.A., Amit, I., Adiconis, X., Fan, L., Raychowdhury, R., Zeng, Q., Chen, Z., Mauceli, E., Hacohen, N., Gnirke, A.,

843 Graupner, N., Jensen, M., Bock, C., Marks, S., Rahmann, S., Beisser, D., Boenigk, J., 2018. Evolution of heterotrophy in chrysophytes as reflected by comparative transcriptomics.

846 Gruber-Vodicka, H.R., Seah, B.K.B., Pruesse, E., 2020. phyloFlash: Rapid Small-Subunit rRNA https://doi.org/10.1111/tpj.12734

Haas, B., 2015. TransDecoder (Find Coding Regions Within Transcripts) [WWW Document]. 
854 Hackl, T., Martin, R., Barenhoff, K., Duponchel, S., Heider, D., Fischer, M.G., 2020. Four highquality draft genome assemblies of the marine heterotrophic nanoflagellate Cafeteria roenbergensis. Sci. Data 7, 1-9. https://doi.org/10.1038/s41597-020-0363-4

Hehenberger, E., Gast, R.J., Keeling, P.J., 2019. A kleptoplastidic dinoflagellate and the tipping point between transient and fully integrated plastid endosymbiosis. Proc. Natl. Acad. Sci. U. S. A. 116, 17934-17942. https://doi.org/10.1073/pnas.1910121116

Hehenberger, E., Tikhonenkov, D. V., Kolisko, M., del Campo, J., Esaulov, A.S., Mylnikov, A.P., Keeling, P.J., 2017. Novel Predators Reshape Holozoan Phylogeny and Reveal the Presence of a Two-Component Signaling System in the Ancestor of Animals. Curr. Biol.

Irwin, N.A.T., 2021. Phylogenomic-analysis [WWW Document]. GitHub. URL 27, 2043-2050.e6. https://doi.org/10.1016/j.cub.2017.06.006

Hickman, C.J., 1970. Biology of Phytophthora Zoospores. Phytopathology. https://doi.org/10.1094/phyto-60-1128

Ho, H.H., Hickman, C.J., 1967. Asexual Reproduction and Behavior of Zoospores of Phytophthora Megasperma Var. Sojae. Can. J. Bot. 45, 1963-1981.

871 Judelson, H.S., Blanco, F.A., 2005. The spores of Phytophthora: Weapons of the plant destroyer. Nat. Rev. Microbiol. 3, 47-58. https://doi.org/10.1038/nrmicro1064

873 Kalyaanamoorthy, S., Minh, B.Q., Wong, T.K.F., Haeseler, A. Von, Jermiin, L.S., 2017.

874 ModelFinder : fast model selection for accurate phylogenetic estimates. Nat. Methods 14. 875 https://doi.org/10.1038/nmeth.4285

876 Kapli, P., Yang, Z., Telford, M.J., 2020. Phylogenetic tree building in the genomic age. Nat. 
Rev. Genet. 21, 428-444. https://doi.org/10.1038/s41576-020-0233-0

878

879

880

881

882

883

884

885

886

887

888

889

890

891

892

893

894

895

896

897

898

899

Katoh, K., Standley, D.M., 2013. MAFFT multiple sequence alignment software version 7:

Improvements in performance and usability. Mol. Biol. Evol. 30, 772-780.

https://doi.org/10.1093/molbev/mst010

Keeling, P.J., 2002. Molecular phylogenetic position of Trichomitopsis termopsidis (Parabasalia) and evidence for the Trichomitopsiinae. Eur. J. Protistol. 38, 279-286. https://doi.org/10.1078/0932-4739-00874

Keeling, P.J., Burki, F., 2019. Progress towards the Tree of Eukaryotes. Curr. Biol. 29, R808R817. https://doi.org/10.1016/j.cub.2019.07.031

Keeling, P.J., Burki, F., Wilcox, H.M., Allam, B., Allen, E.E., Amaral-Zettler, L.A., Armbrust, E.V., Archibald, J.M., Bharti, A.K., Bell, C.J., Beszteri, B., Bidle, K.D., Cameron, C.T., Campbell, L., Caron, D.A., Cattolico, R.A., Collier, J.L., Coyne, K., Davy, S.K., Deschamps, P., Dyhrman, S.T., Edvardsen, B., Gates, R.D., Gobler, C.J., Greenwood, S.J., Guida, S.M., Jacobi, J.L., Jakobsen, K.S., James, E.R., Jenkins, B., John, U., Johnson, M.D., Juhl, A.R., Kamp, A., Katz, L.A., Kiene, R., Kudryavtsev, A., Leander, B.S., Lin, S., Lovejoy, C., Lynn, D., Marchetti, A., McManus, G., Nedelcu, A.M., Menden-Deuer, S., Miceli, C., Mock, T., Montresor, M., Moran, M.A., Murray, S., Nadathur, G., Nagai, S., Ngam, P.B., Palenik, B., Pawlowski, J., Petroni, G., Piganeau, G., Posewitz, M.C., Rengefors, K., Romano, G., Rumpho, M.E., Rynearson, T., Schilling, K.B., Schroeder, D.C., Simpson, A.G.B., Slamovits, C.H., Smith, D.R., Smith, G.J., Smith, S.R., Sosik, H.M., Stief, P., Theriot, E., Twary, S.N., Umale, P.E., Vaulot, D., Wawrik, B., Wheeler, G.L., Wilson, W.H., Xu, Y., Zingone, A., Worden, A.Z., 2014. The Marine Microbial Eukaryote Transcriptome Sequencing Project (MMETSP): Illuminating the Functional 
Diversity of Eukaryotic Life in the Oceans through Transcriptome Sequencing. PLoS Biol.

Ko, W.H., Chase, L.L., 1973. Aggregation of Zoospores of Phytophthora palmivora. J. Gen. Microbiol. 78, 79-82. https://doi.org/10.1099/00221287-78-1-79

904 Kobert, K., Salichos, L., Rokas, A., Stamatakis, A., 2016. Computing the Internode Certainty and Related Measures from Partial Gene Trees. Mol. Biol. Evol. 33, 1606-1617.

Kolodziej, K., Stoeck, T., 2007. Cellular identification of a novel uncultured marine stramenopile (MAST-12 clade) small-subunit rRNA gene sequence from a Norwegian

Krings, M., Taylor, T.N., Dotzler, N., 2011. The fossil record of the peronosporomycetes estuary by use of fluorescence in situ hybridization-scanning electron microscopy. Appl.

Kühn, S., Medlin, L., Eller, G., Subunit, N.S., Dna, R., Kühn, S., Medlin, L., Eller, G., 2004. Phylogenetic position of the parasitoid nanoflagellate Pirsonia inferred from nuclearencoded small subunit ribosomal DNA and a description of Pseudopirsonia n. gen. and Pseudopirsonia mucosa (Drebes) comb.nov. Protist 155, 143-156.

918 Laetsch, D.R., Blaxter, M.L., 2017. BlobTools : Interrogation of genome assemblies [version 1 ; 919 peer review : 2 approved with reservations]. F1000Research 6, 1-16.

920 https://doi.org/10.12688/f1000research.12232.1

921 Lartillot, N., Brinkmann, H., Philippe, H., 2007. Suppression of long-branch attraction artefacts 922 in the animal phylogeny using a site-heterogeneous model. BMC Evol. Biol. 7, 1-14. 
924 Lartillot, N., Lepage, T., Blanquart, S., 2009. PhyloBayes 3: A Bayesian software package for

925 phylogenetic reconstruction and molecular dating. Bioinformatics 25, 2286-2288.

926 https://doi.org/10.1093/bioinformatics/btp368

927 Lartillot, N., Philippe, H., 2004. A Bayesian mixture model for across-site heterogeneities in the 928 amino-acid replacement process. Mol. Biol. Evol. 21, 1095-1109. https://doi.org/10.1093/molbev/msh112

930 Leipe, D.D., Tong, S.M., Goggin, C.L., Slemenda, S.B., Pieniazek, N.J., Sogin, M.L., 1996. 16S-

931 like rDNA sequences from Developayella elegans, Labyrinthuloides haliotidis, and

932 Proteromonas lacertae confirm that the stramenopiles are a primarily heterotrophic group.

933 Eur. J. Protistol. 32, 449-458. https://doi.org/10.1016/S0932-4739(96)80004-6

934 Leonard, G., Labarre, A., Milner, D.S., Monier, A., Soanes, D., Wideman, J.G., Maguire, F.,

935 Stevens, S., Sain, D., Grau-Bové, X., Sebé-Pedrós, A., Stajich, J.E., Paszkiewicz, K.,

936 Brown, M.W., Hall, N., Wickstead, B., Richards, T.A., 2018. Comparative genomic

937 analysis of the 'pseudofungus 'Hyphochytrium catenoides. Open Biol. 8.

$938 \quad$ https://doi.org/10.1098/rsob.170184

939 Lin, Y.-C., Campbell, T., Chung, C.-C., Gong, G.-C., Chiang, K.-P., Worden, A.Z., 2012.

940 Distribution Patterns and Phylogeny of Marine Stramenopiles in the. Appl. Environ.

941 Microbiol. 3387-3399. https://doi.org/10.1128/AEM.06952-11

942 Massana, R., Campo, J., Sieracki, M.E., Audic, S., Logares, R., 2014. Exploring the uncultured

943 microeukaryote majority in the oceans : reevaluation of ribogroups within stramenopiles.

944 Int. Soc. Microb. Ecol. 8, 854-866. https://doi.org/10.1038/ismej.2013.204

945 Massana, R., Castresana, J., Balague, V., Guillou, L., Romari, K., Groisillier, A., Valentin, K., 
949 Matari, N.H., Blair, J.E., 2014. A multilocus timescale for oomycete evolution estimated under 950 three distinct molecular clock models. BMC Evol. Biol. 14, 1-11. https://doi.org/10.1186/1471-2148-14-101

Medlin, L., Elwood, H.J., Stickel, S., Sogin, M.L., 1988. The characterization of enzymatically amplified eukaryotic 16S-like rRNA-coding regions. Gene 71, 491-499. https://doi.org/10.1016/0378-1119(88)90066-2

Mitra, A., Flynn, K.J., Tillmann, U., Raven, J.A., Caron, D., Stoecker, D.K., Not, F., Hansen, P.J., Hallegraeff, G., Sanders, R., Wilken, S., McManus, G., Johnson, M., Pitta, P., Våge,

Nguyen, L.T., Schmidt, H.A., Von Haeseler, A., Minh, B.Q., 2015. IQ-TREE: A fast and effective stochastic algorithm for estimating maximum-likelihood phylogenies. Mol. Biol.

964 Noguchi, F., Tanifuji, G., Brown, M.W., Fujikura, K., Takishita, K., 2016. Complex evolution of two types of cardiolipin synthase in the eukaryotic lineage stramenopiles. Mol. Phylogenet. Evol. 101, 133-141. https://doi.org/10.1016/j.ympev.2016.05.011 eukaryotes. BioEssays 35, 339-347. https://doi.org/DOI 10.1002/bies.201200143 
969 Picelli, S., Faridani, O.R., Björklund, Å.K., Winberg, G., Sagasser, S., Sandberg, R., 2014. Full-

970 length RNA-seq from single cells using Smart-seq2. Nat. Protoc. 9, 171-181.

$971 \quad$ https://doi.org/10.1038/nprot.2014.006

972 Quang, L.S., Gascuel, O., Lartillot, N., 2008. Empirical profile mixture models for phylogenetic

973 reconstruction. Bioinformatics 24, 2317-2323.

974 https://doi.org/10.1093/bioinformatics/btn445

975 Quast, C., Pruesse, E., Yilmaz, P., Gerken, J., Schweer, T., Yarza, P., Peplies, J., Glöckner, F.O.,

976 2013. The SILVA ribosomal RNA gene database project: Improved data processing and

977 web-based tools. Nucleic Acids Res. 41, 590-596. https://doi.org/10.1093/nar/gks 1219

978 Raghukumar, S., 1992. Bacterivory: a novel dual role for thraustochytrids in the sea. Mar. Biol.

979 113, 165-169. https://doi.org/10.1007/BF00367650

980 Richards, T.A., Talbot, N.J., 2013. Horizontal gene transfer in osmotrophs: playing with public

981 goods. Nat. Rev. Microbiol. 11, 720-727.

982 https://doi.org/http://dx.doi.org.ezproxy.library.ubc.ca/10.1038/nrmicro3108

983 Roure, B., Baurain, D., Philippe, H., 2013. Impact of missing data on phylogenies inferred from

984 empirical phylogenomic data sets. Mol. Biol. Evol. 30, 197-214.

985 https://doi.org/10.1093/molbev/mss208

986 Roure, B., Rodriguez-Ezpeleta, N., Philippe, H., 2007. SCaFoS: A tool for selection,

987 concatenation and fusion of sequences for phylogenomics. BMC Evol. Biol. 7, 1-12.

988 https://doi.org/10.1186/1471-2148-7-S1-S2

989 Roy, R.S., Price, D.C., Schliep, A., Cai, G., Korobeynikov, A., Yoon, H.S., Yang, E.C.,

990 Bhattacharya, D., 2014. Single cell genome analysis of an uncultured heterotrophic

991 stramenopile. Sci. Rep. 4, 1-8. https://doi.org/10.1038/srep04780 
992

993

994

995

996

997

998

999

1000

1001

1002

1003

1004

1005

1006

1007

1008

1009

1010

1011

1012

1013

1014

Savory, A.I.M., Grenville-Briggs, L.J., Wawra, S., Van West, P., Davidson, F.A., 2014. Autoaggregation in zoospores of Phytophthora infestans: The cooperative roles of bioconvection and chemotaxis. J. R. Soc. Interface 11. https://doi.org/10.1098/rsif.2014.0017

Savory, F., Leonard, G., Richards, T.A., 2015. The Role of Horizontal Gene Transfer in the Evolution of the Oomycetes. PLoS Pathog. 11, 1-6. https://doi.org/10.1371/journal.ppat.1004805

Savory, F.R., Milner, D.S., Miles, D.C., Richards, T.A., 2018. Ancestral function and diversification of a horizontally acquired oomycete carboxylic acid transporter. Mol. Biol. Evol. 35, 1887-1900. https://doi.org/10.1093/molbev/msy082

Schnepf, E., Drebes, G., Elbrachter, M., 1990. Pirsonia guinardiae , gen. et spec. nov.: A parasitic flagellate on the marine diatom Guinardia flaccida with an unusual mode of food uptake. Helgolander Meeresunters 44, 275-293. https://doi.org/10.1007/BF02365468

Schweikert, M., Schnepf, E., 1997. Light and electron microscopical observations on Pirsonia punctigerae spec. nov., a Nanoflagellate feeding on the marine centric diatom Thalassiosira punctigera. Eur. J. Protistol. 33, 168-177. https://doi.org/10.1016/S0932-4739(97)80033-8

Sebé-Pedrós, A., Irimia, M., del Campo, J., Parra-Acero, H., Russ, C., Nusbaum, C., Blencowe, B.J., Ruiz-Trillo, I., 2013. Regulated aggregative multicellularity in a close unicellular relative of metazoa. Elife 2013, 1-20. https://doi.org/10.7554/eLife.01287

Seeleuthner, Y., Mondy, S., Lombard, V., Carradec, Q., Pelletier, E., Wessner, M., Leconte, J., Mangot, J.-F., Poulain, J., Labadie, K., Logares, R., Sunagawa, S., de Berardinis, V., Salanoubat, M., Dimier, C., Kandels-Lewis, S., Picheral, M., Searson, S., Pesant, S., Poulton, N., Stepanauskas, R., Bork, P., Bowler, C., Hingamp, P., Sullivan, M.B., Iudicone, D., Massana, R., Aury, J.-M., Henrissat, B., Karsenti, E., Jaillon, O., Sieracki, M., de 
1015

1016

1017

1018

1019

1020

1021

1022

1023

1024

1025

1026

1027

1028

1029

1030

1031

1032

1033

1034

1035

1036

1037

Vargas, C., Wincker, P., 2018. Single-cell genomics of multiple uncultured stramenopiles reveals underestimated functional diversity across oceans. Nat. Commun. 9, 310. https://doi.org/10.1038/s41467-017-02235-3

Seemann, T., 2007. Barrnap 0.9: BAsic Rapid Ribosomal RNA Predictor [WWW Document]. GitHub. URL https://github.com/tseemann/barrnap

Shimodaira, H., 2002. An approximately unbiased test of phylogenetic tree selection. Syst. Biol. 51, 492-508. https://doi.org/10.1080/10635150290069913

Shiratori, T., Nakayama, T., Ishida, K. ichiro, 2015. A New Deep-branching Stramenopile, Platysulcus tardus gen. nov., sp. nov. Protist 166, 337-348. https://doi.org/10.1016/j.protis.2015.05.001

Shiratori, T., Thakur, R., Ishida, K., 2017. Pseudophyllomitus vesiculosus (Larsen and Patterson 1990) Lee, 2002, a poorly studied phagotrophic biflagellate is the first characterized member of stramenoile environmental clade MAST-6. Protist 168, 439-451. https://doi.org/10.1016/j.protis.2017.06.004

Sibbald, S.J., Archibald, J.M., 2017. More protist genomes needed. Nat. Ecol. Evol. 1, 1-3. https://doi.org/10.1038/s41559-017-0145

Simão, F.A., Waterhouse, R.M., Ioannidis, P., Kriventseva, E. V., Zdobnov, E.M., 2015. BUSCO: Assessing genome assembly and annotation completeness with single-copy orthologs. Bioinformatics 31, 3210-3212. https://doi.org/10.1093/bioinformatics/btv351

Stiller, J.W., Huang, J., Ding, Q., Tian, J., Goodwillie, C., 2009. Are algal genes in nonphotosynthetic protists evidence of historical plastid endosymbioses? BMC Genomics 10, 484. https://doi.org/10.1186/1471-2164-10-484

Sugimoto, H., Endoh, H., 2006. Analysis of fruiting body development in the aggregative ciliate 
1038

1039

1040

1041

1042

1043

1044

1045

1046

1047

1048

1049

1050

1051

1052

1053

1054

1055

1056

1057

1058

1059

1060

Sorogena stoianovitchae (Ciliophora, Colpodea). J. Eukaryot. Microbiol. 53, 96-102. https://doi.org/10.1111/j.1550-7408.2005.00077.x

Thakur, R., Shiratori, T., Ishida, K. ichiro, 2019. Taxon-rich Multigene Phylogenetic Analyses Resolve the Phylogenetic Relationship Among Deep-branching Stramenopiles. Protist 170, 125682. https://doi.org/10.1016/j.protis.2019.125682

Tikhonenkov, D. V., Janouškovec, J., Mylnikov, A.P., Mikhailov, K. V., Simdyanov, T.G., Aleoshin, V. V., Keeling, P.J., 2014. Description of Colponema vietnamica sp.n. and Acavomonas peruviana n. gen. n. sp., Two New Alveolate Phyla (Colponemidia nom. nov. and Acavomonidia nom.nov.) and Their Contributions to Reconstructing the Ancestral State of Alveolates and Eukaryotes. PLoS One 9. https://doi.org/10.1371/journal.pone.0095467

Tikhonenkov, D. V., Mazei, Y.A., Embulaeva, E.A., 2008. Degradation succession of heterotrophic flagellate communities in microcosms. Zh Obs. Biol 69, 57-64.

Tikhonenkov, D. V, Janou, J., Keeling, P.J., Mylnikov, A.P., 2016. The Morphology, Ultrastructure and SSU rRNA Gene Sequence of a New Freshwater Flagellate, Neobodo borokensis n . sp . ( Kinetoplastea , Excavata ). J. Eukaryot. Microbiol. 63, 220-232. https://doi.org/10.1111/jeu.12271

Tong, S.M., 1995. Developayella elegans nov. gen., nov. spec., a New Type of Heterotrophic Flagellate from Marine Plankton. Eur. J. Protistol. 31, 24-31. https://doi.org/10.1016/S0932-4739(11)80352-4

Torruella, G., Grau-Bové, X., Moreira, D., Karpov, S.A., Burns, J.A., Sebé-Pedrós, A., Völcker, E., López-García, P., 2018. Global transcriptome analysis of the aphelid Paraphelidium tribonemae supports the phagotrophic origin of fungi. Commun. Biol. 1, 1-11. https://doi.org/10.1038/s42003-018-0235-z 
1061

1062

1063

1064

1065

1066

1067

1068

1069

1070

1071

1072

1073

1074

1075

1076

1077

1078

1079

1080

1081

1082

1083

Tsui, C.K.M., Marshall, W., Yokoyama, R., Honda, D., Lippmeier, J.C., Craven, K.D., Peterson, P.D., Berbee, M.L., 2009. Labyrinthulomycetes phylogeny and its implications for the evolutionary loss of chloroplasts and gain of ectoplasmic gliding. Mol. Phylogenet. Evol. 50, 129-140. https://doi.org/10.1016/j.ympev.2008.09.027

Tyler, B.M., Tripathy, S., Zhang, X., Dehal, P., Jiang, R.H.Y., Aerts, A., Arredondo, F.D., Baxter, L., Bensasson, D., Beynon, J.L., Chapman, J., Damasceno, C.M.B., Dorrance, A.E., Dou, D., Dickerman, A.W., Dubchak, I.L., Garbelotto, M., Gijzen, M., Gordon, S.G., Govers, F., Grunwald, N.J., Huang, W., Ivors, K.L., Jones, R.W., Kamoun, S., Krampis, K., Lamour, K.H., Lee, M.K., McDonald, W.H., Medina, M., Meijer, H.J.G., Nordberg, E.K., Maclean, D.J., Ospina-Giraldo, M.D., Morris, P.F., Phuntumart, V., Putnam, N.H., Rash, S., Rose, J.K.C., Sakihama, Y., Salamov, A.A., Savidor, A., Scheuring, C.F., Smith, B.M., Sobral, B.W.S., Terry, A., Torto-Alalibo, T.A., Win, J., Xu, Z., Zhang, H., Grigoriev, I. V., Rokhsar, D.S., Boore, J.L., 2006. Phytophthora genome sequences uncover evolutionary origins and mechanisms of pathogenesis. Science (80-. ). 313, 1261-1266. https://doi.org/10.1126/science. 1128796

Wang, H.C., Minh, B.Q., Susko, E., Roger, A.J., 2018. Modeling Site Heterogeneity with Posterior Mean Site Frequency Profiles Accelerates Accurate Phylogenomic Estimation. Syst. Biol. 67, 216-235. https://doi.org/10.1093/sysbio/syx068

Wang, Q., Sun, H., Huang, J., 2017. Re-analyses of "algal” genes suggest a complex evolutionary history of oomycetes. Front. Plant Sci. 8, 1-14. https://doi.org/10.3389/fpls.2017.01540

Wawrzyniak, I., Courtine, D., Osman, M., Hubans-Pierlot, C., Cian, A., Nourrisson, C., Chabe, M., Poirier, P., Bart, A., Polonais, V., Delgado-Viscogliosi, P., El Alaoui, H., Belkorchia, 
1084

1085

1086

1087

1088

1089

1090

1091

1092

1093

1094

1095

1096

1097

1098

1099

1100

1101

1102

1103

1104

1105

1106

1107

A., van Gool, T., Tan, K.S.W., Ferreira, S., Viscogliosi, E., Delbac, F., 2015. Draft genome sequence of the intestinal parasite Blastocystis subtype 4-isolate WR1. Genomics Data 4, 22-23. https://doi.org/10.1016/j.gdata.2015.01.009

Weiler, B.A., Sa, E.L., Sieracki, M.E., Massana, R., del Campo, J., 2020. Mediocremonas mediterraneus ,a new member within the Developea. J. Eukaryot. Microbiol. 1, 0-2. https://doi.org/10.1111/jeu.12825

Whelan, S., Irisarri, I., Burki, F., 2018. PREQUAL: Detecting non-homologous characters in sets of unaligned homologous sequences. Bioinformatics 34, 3929-3930. https://doi.org/10.1093/bioinformatics/bty448

Yubuki, N., Pánek, T., Yabuki, A., Čepička, I., Takishita, K., Inagaki, Y., Leander, B.S., 2015. Morphological Identities of Two Different Marine Stramenopile Environmental Sequence Clades: Bicosoeca kenaiensis (Hilliard, 1971) and Cantina marsupialis (Larsen and Patterson, 1990) gen. nov., comb. nov. J. Eukaryot. Microbiol. 62, 532-542. https://doi.org/10.1111/jeu.12207

Zheng, L., Mackrill, J.J., 2016. Calcium signaling in oomycetes: An evolutionary perspective. Front. Physiol. 7, 1-7. https://doi.org/10.3389/fphys.2016.00123

Zhou, Y., Rodrigue, N., Lartillot, N., Philippe, H., 2007. Evaluation of the models handling heterotachy in phylogenetic inference. BMC Evol. Biol. 7, 1-13. https://doi.org/10.1186/1471-2148-7-206

Zmitrovich, I. V, 2018. The Oomycota phenomenon, in: IV (XII) International Botanical Conference of Young Scientists. Mycology and lichenology, St. Petersburg, pp. 188-190. 


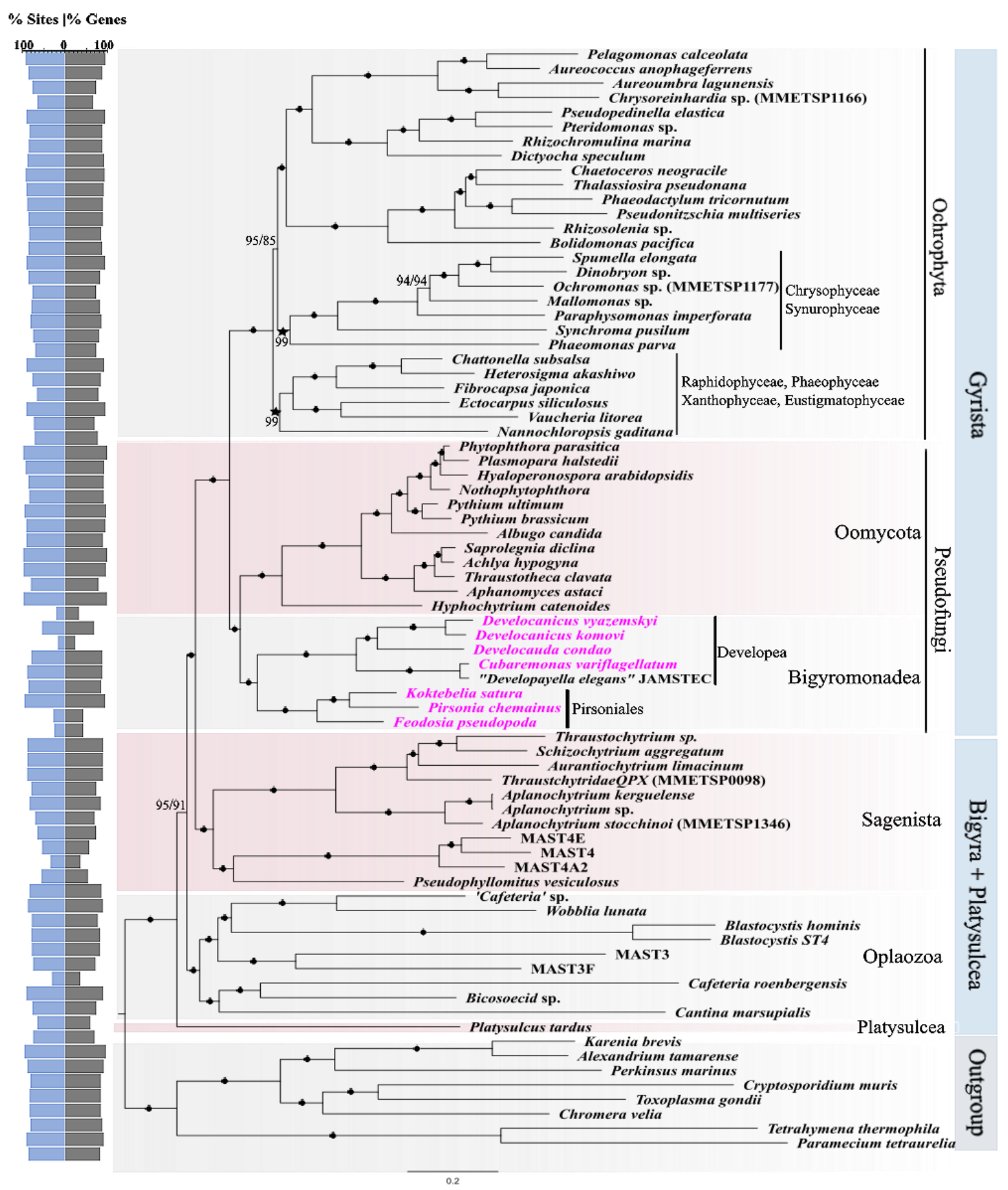

Figure 1. Multi-gene phylogenomic tree of stramenopiles with the seven new transcriptomes

1110 (pink) added to Gyrista, consisting of the concatenated alignments of 247 genes of 76 taxa. The

1111 tree was reconstructed using the Maximum-likelihood (ML) analysis, under the site-heterogenous

1112 model, $\mathrm{LG}+\mathrm{C} 60+\mathrm{F}+\mathrm{G} 4+\mathrm{PMSF}$, implemented in IQ-Tree. Branch support was calculated using 
1113 non-parametric PMSF 100 standard bootstrap (STB). Branches with $\geq 99 \%$ STB for both

1114 approaches are marked with black bullets while others are labelled as "Approach 1 STB/Approach

11152 STB". The topology of the trees generated from the two approaches were the same except the

1116 positions of Raphidophyceae, Phaeophyceae, Xanthophyceae + Eustigmatophacea and

1117 Chrysophyceae+Synurophceae, which were swapped in the tree reconstructed based on the dataset

1118 processed using approach 2 (i.e., Prequal/Divvier method); denoted by star symbols (Fig. S1). The

1119 percent sites (blue) and genes (grey) present for each transcriptome is depicted on the back-to-

1120 back bar plot on the left.

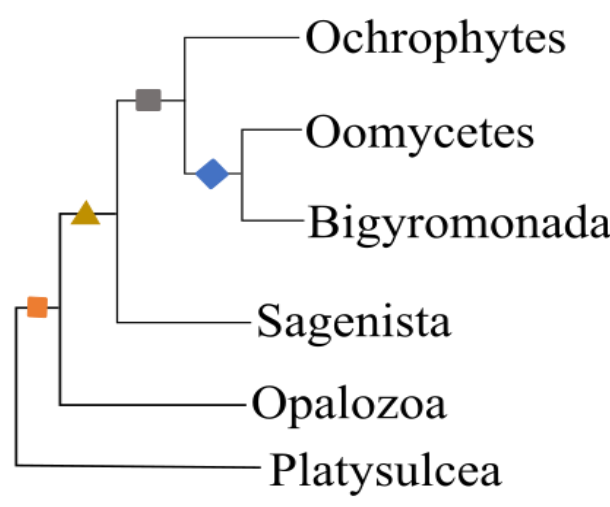

Platysulcea

Figure 2. Summary of ultrafast bootstrap (UFB) with incremental removal of fast-evolving sites,

1125 based on the dataset processed with approach 1. Schematic representation the stramenopiles ML

1126 tree (left) with each branch marked with different shapes and colours. The line plot (right) showing

1127 the change in UFB for each branch when fast-evolving sites were incrementally removed by $5 \%$.

1128 The monophyly of Gyrista shows full support throughout while the UFB increases incrementally

1129 for 'Sagenista' and 'Platysulcea'. 
Table 1. Approximately unbiased (AU) tests on tree constraints based on approach 1 dataset.

Approach 1 (MAFFT L-INS-i and trimAl -g 0.8)

\begin{tabular}{lrrr}
\hline Constrained Tree & p-AU & \multicolumn{1}{l}{$\log \mathrm{L}$} & $\Delta \log \mathrm{L}$ \\
\hline Unconstrained ML tree & 0.78 & -3935691.338 & 0 \\
ML tree & 0.759 & -3935691.338 & 0.00089261 \\
Chain 1 (C+S+Pi),(R+P+X+E) & 0.0541 & -3935828.083 & 136.75 \\
Chain 1 Modified (Bigyromonada+oomycetes) & 0.267 & -3935763.845 & 72.508 \\
Chain 2 (C+S+Pi+E),(R+P+X) & $\mathbf{0 . 0 2 9 7}$ & -3935859.39 & 168.05 \\
Chain 2 Modified (Bigyromonada+oomycetes) & 0.0924 & -7871604.549 & 108.01 \\
Chain 3 (R+P+X+E),(C+S) & $\mathbf{0 . 0 1 1 9}$ & -3935874.998 & 183.66 \\
Chain 3 Modified (Bigyromonada+oomycetes) & 0.0717 & -3935805.205 & 113.87 \\
Chain 4 (C+S+E),(R+P+X) & $\mathbf{0 . 0 1 8 6}$ & -3935860.003 & 168.67 \\
Chain 4 Modified (Bigyromonada+oomycetes) & 0.108 & -3935765.741 & 74.404 \\
\hline
\end{tabular}

1131 Except, the unconstrained ML tree, each tree was constrained under LG+C60+F+G4 using IQ-TREE with the

1132 approach 1 dataset. Chain 1 to chain 4 are generated from Bayesian analyses and contain

1133 (bigyromonada+ochrophytes). "Chain 1 Modified" to "Chain4 modified" contain hypothetical

1134 (bigyromonada+oomycetes) with the rest of topology remaining the same with their corresponding chains. Each

1135 unmodified chain is listed with different topology of Chyrisista as represented in Fig. S2. The unconstrained tree is

1136 based on ML tree reconstructed under $\mathrm{LG}+\mathrm{C} 60+\mathrm{F}+\mathrm{G} 4+\mathrm{PMSF}$ as presented in Fig. 1. The p-AU values were

1137 calculated using the AU test with 10,000 RELL bootstrap replicates, implemented in IQ-TREE. The maximum log

1138 likelihoods $(\log \mathrm{L})$ of each constrained and their differences $(\Delta \log \mathrm{L})$ compared to the unstrained tree are listed.

1139 Constraints with P-values lower than 0.05 are rejected, indicating confidence interval below $95 \%$ (marked bold).

1140 Raphidophyceae (R), Eustigmatophyceae (E), Chrysophyceae (C), Synurophyceae (S), Phaeophyceae (P),

1141 Pinguiophyceae (Pi), and Xanthophyceae (X).

1142 
bioRxiv preprint doi: https://doi.org/10.1101/2021.11.17.469027; this version posted November 19, 2021. The copyright holder for this preprint (which was not certified by peer review) is the author/funder, who has granted bioRxiv a license to display the preprint in perpetuity. It is made available under aCC-BY-NC-ND 4.0 International license.

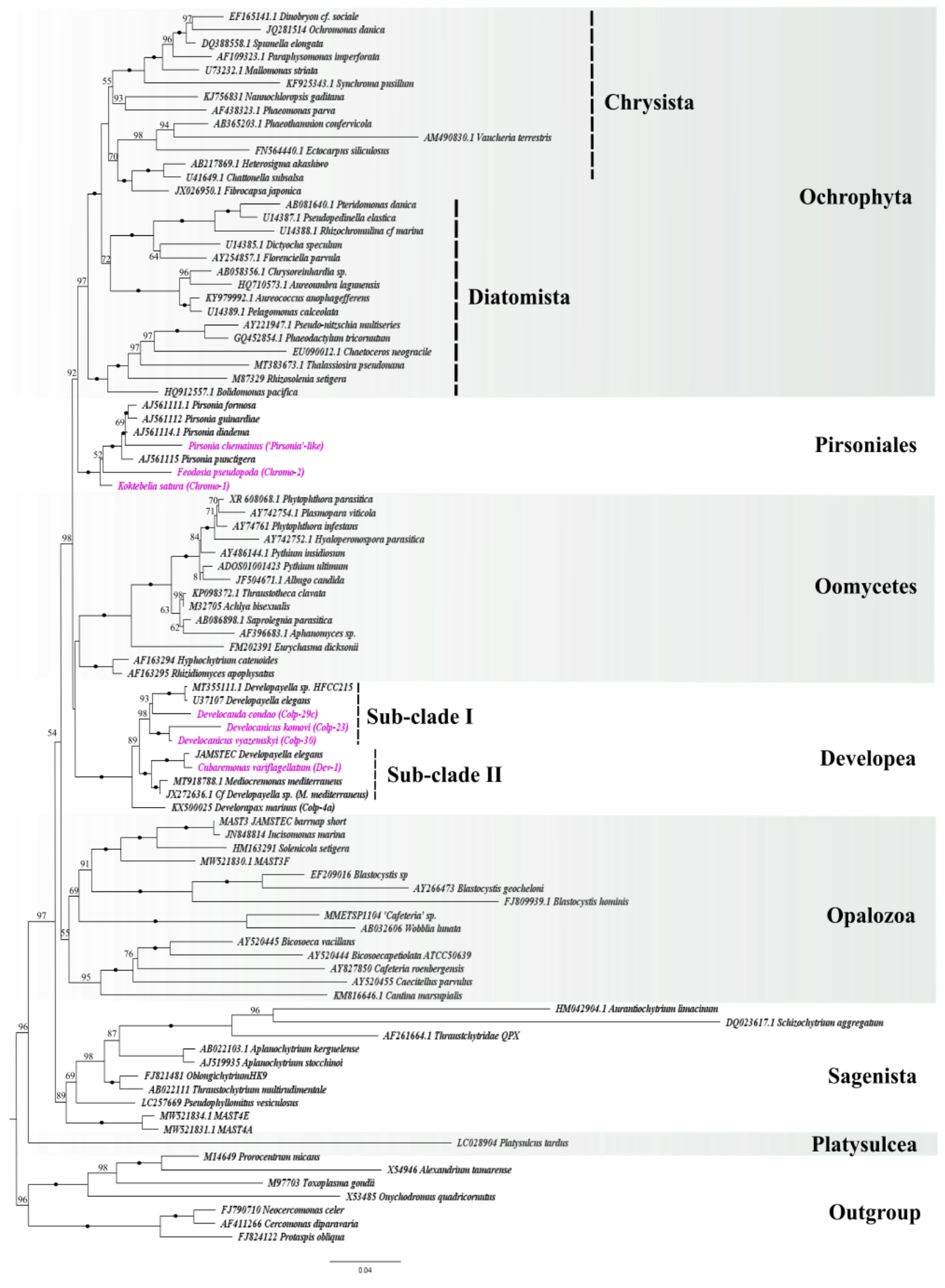


1144 Figure 3. ML tree reconstructed from a 18S rRNA gene alignment of 92 taxa (1650 sites), under

1145 BIC: TIM2+R6 with 1000 UFB. Branch support with $\geq 99 \%$ UFB is marked with black bullets

1146 while the values less than $50 \%$ are not shown. The seven new species described in this study are

1147 marked as pink: Pirsoniales forming a sisterhood with Ochrophytes and Developea forming a sister

1148 clade to Oomycetes. Within Developea, two previously assigned Developayella species

1149 (JAMSTEC transcriptome and the U37107 SSU rRNA sequence) are split into two sub-clades, in 1150 which the four novel Developea species are positioned. 

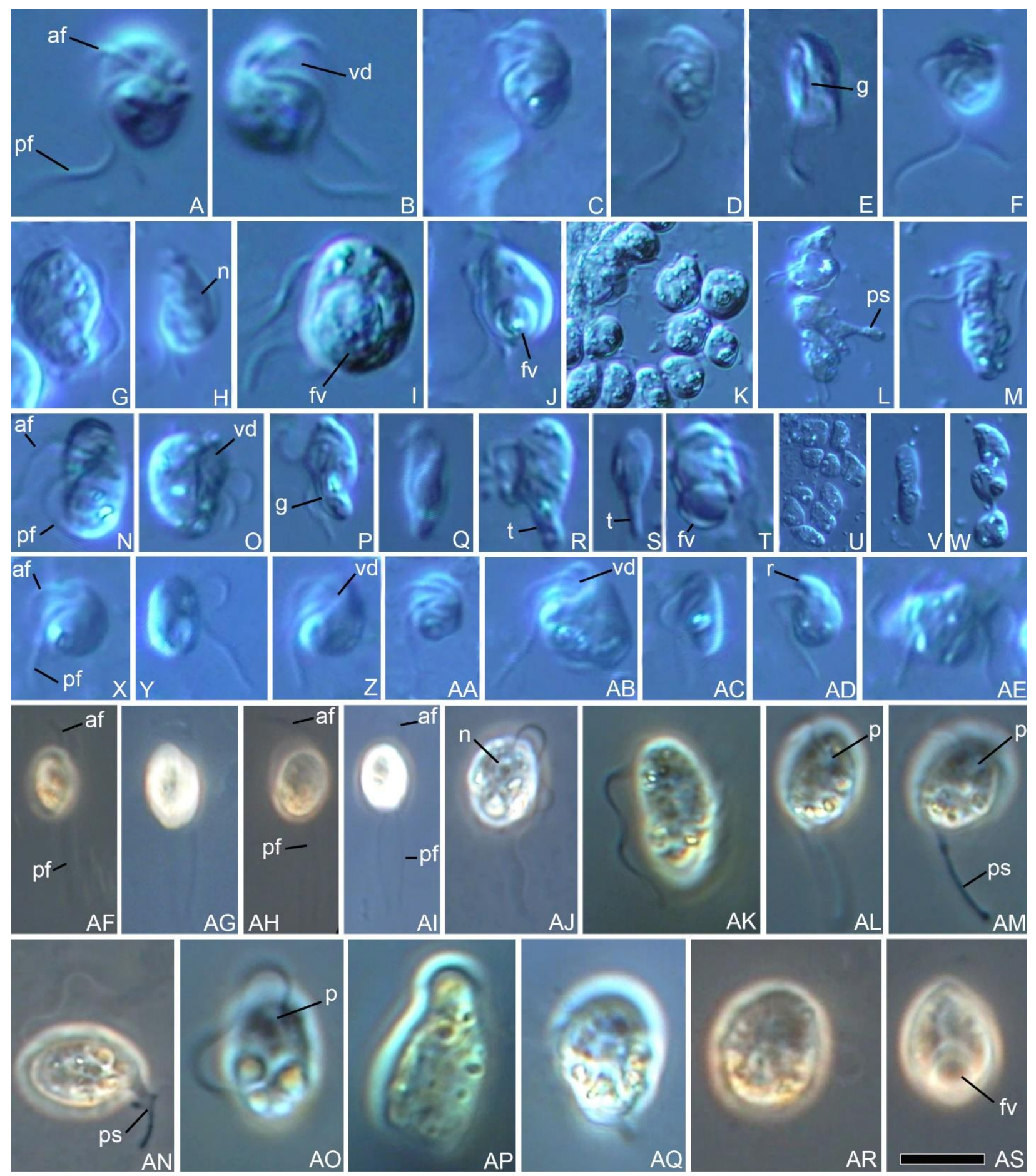

Figure 4. Morphology of novel phagoheterotrophic stramenopiles. A, B. Develocanicus

1154 vyazemskyi, general cell view with flagella (anterior flagellum [af] and posterior flagellum [pf])

1155 and ventral depression [vd]. C-M. Develocanicus komovi, C-F - general cell view with flagella

1156 and ventral depression, shallow wide groove $[\mathrm{g}]$ is visible in $(\mathrm{E}), \mathrm{G}$ - lying cell with posterior 
1157 flagellum [pf] beating with a slow sinusoidal wave, $\mathrm{H}-\mathrm{J}$ - cells with medial nucleus [n] $(\mathrm{H})$ and

1158 large food vacuoles [fv] (I, J), K - cell aggregation, L - aggregated cells with pseudopodia [ps],

$1159 \mathrm{M}-$ transverse binary fission. N-W. Develocauda condao, N-P - general cell view with two

1160 flagella and ventral depression, $\mathrm{Q}$ - rod-shaped cell, R,S - cells with pointed 'tail-like' [t] posterior

1161 end, T - cells with large food vacuole, $\mathrm{U}$ - cell aggregation, $\mathrm{V}$ - transverse binary fission, W -

1162 partially fused cells. X-AE. Cubaremonas variflagellatum, X-AA - general cell view with

1163 flagella, AB - cell with conspicuous ventral depression, AC, AD - starving cells with small

1164 rostrum $[\mathrm{r}](\mathrm{AD}), \mathrm{AE}-$ division into 4 cells. AF, AG, AJ - AS. Feodosia pseudopoda, AF, AG -

1165 typical fast swimming cell with two flagella, AJ, AK, AO - lying cells with sinusoid shaped

1166 flagella, AL-AN - cells with pseudopodia and anterior pit [p] (AL, AM), AP-AR - metabolic

1167 cells, AS - cell with large food vacuole. AH. Koktebelia satura, typical fast swimming cell with

1168 two flagella. AI. Pirsonia chemainus, typical fast swimming cell with two flagella. Scale bar: A,

$1169 \mathrm{~B}, \mathrm{R}, \mathrm{AK}, \mathrm{AP}, \mathrm{AQ}, \mathrm{AS}-8 \mu \mathrm{m} ; \mathrm{C}-\mathrm{H}, \mathrm{J}, \mathrm{N}, \mathrm{P}, \mathrm{Q}, \mathrm{X}-\mathrm{AA}, \mathrm{AC}, \mathrm{AD}-7 \mu \mathrm{m} ; \mathrm{I}, \mathrm{O}, \mathrm{T}, \mathrm{AB}-5 \mu \mathrm{m} ; \mathrm{K}$, 